\title{
THE SYNTAX OF SINGLE WORDS: EVIDENCE FROM A PATIENT WITH A SELECTIVE FUNCTION WORD READING DEFICIT
}

\author{
Judit Druks \\ Birkbeck College, University of London, UK
}

Karen Froud

University College London, UK

\begin{abstract}
We describe the reading performance of a patient who has selective deficits for reading nonwords, function words, and morphologically complex words in isolation. His reading of highly abstract nouns and verbs, however, is relatively well preserved. He can recognise and comprehend the meaning of written function words, of derivational morphology, and of most inflectional morphology. We suggest that his deficit in reading grammatical morphemes is unrelated to his problems in reading nonwords and cannot be explained by their low semanticity and imageability. The patient's speech is ungrammatical but is not devoid of grammatical morphemes and his reading of functional elements improves when these are presented within the context of sentences. We argue that syntactic information relevant to individual lexical items including information about how the word may potentially be used within a phrase must be accessed during single word reading tasks (e.g., Levelt, 1989). This is particularly difficult for function words due to their linguistic specification, which is different from that of lexical categories (Chomsky, 1995). Both linguistic theory and Garrett's (e.g., 1982) model of sentence processing account for the patient's improved reading of function words in the context of sentences.
\end{abstract}

\section{INTRODUCTION}

Grammatical morphemes are known to be vulnerable in both the speech and reading of aphasic patients. Although the deficits in reading grammatical morphemes and using them in speech are, most probably, related, there have been few links between research into reading and speech production deficits. While the omission of grammatical morphemes by agrammatic patients is well documented and there have been numerous attempts at explaining the phenomenon (e.g., Grodzinsky, 1990; Isserlin, 1922; Kean, 1977; Ouhalla, 1993), considerably less effort has been put into explaining the deficit in reading grammatical morphemes by deep dyslexic and (some) phonological dyslexic patients (but see Morton \& Patterson, 1980; Silverberg, Vigliocco, Insalaco, \& Garrett, 1998).

The present paper is devoted to this issue. We will document the reading pattern of one patient and examine in detail his ability to use free and bound

Requests for reprints should be addressed to Judit Druks, School of Psychology, Birkbeck College, University of London, Malet Street, London WC1E 7HX, UK (Email: j.druks@bbk.ac.uk).

We are very grateful to MC for participating in this study. We also thank the Acting Editor and the Referees of Cognitive Neuropsychology for their detailed and constructive comments to this paper and our colleagues-Neil Smith, Jackie Masterson, Gabriella Vigliocco, and Gerhard Blanken—for reading and commenting on earlier versions of the paper., 
grammatical morphemes in connected speech, in reading single words and sentences, and in comprehending them. We will assess previous explanations of the grammatical morphemes deficit in acquired dyslexia and suggest alternative accounts.

Patterson (1982) linked the function word deficit to the nonword reading deficit, suggesting that function words (even by normal readers) are not read via the lexical/semantic route but via the sublexical route. This would entail that all patients with a deficit in reading nonwords would have a deficit in reading function words too. Funnell (1983) argued against this position because, despite demonstrating a total inability to read nonwords, her patient, WB, had no problems in reading function words and affixed words. Caramazza, Miceli, Silveri, and Laudanna (1985), having studied two Italian patients, made a claim similar to Funnell's, and five phonological dyslexic patients studied by Berndt, Haendiges, Mitchum, and Wayland (1996) also had no notable function word deficit. Thus, there are a number of recorded cases in which the reading of nonwords and of grammatical morphemes dissociate (see also the cases of BTT, Shallice \& Warrington, 1980, and of RE, Campbell \& Butterworth, 1985).

Friedman (1995) distinguished between two types of phonological dyslexic patients, and is able to account for both the presence and absence of the grammatical morpheme deficit. One type of patients' deficit in nonword reading is due to impairments of the phonological representations themselves; these patients have no grammatical morpheme deficit. Only those patients who, due to an impairment of the direct route between the orthographic and phonological lexicons, are forced to access the phonological representations indirectly via the semantic system, will have a selective deficit in reading function words. The reason for this, according to Friedman, is that since function words carry little meaning ("words with less densely, interrelated associative networks"), they are "less accessible in the semantic system" (p. 198). In the Triangle model (Patterson, Suzuki, \& Wydell, 1996; Sasanuma, Ito, Patterson, \& Ito, 1996), deficits in nonword reading are always due to a general phonological deficit. As the phonological level is dysfunc- tional, adequate semantic activation is crucial for word production. Function words (and abstract words too), which are lacking in rich semantic specifications, cannot adequately activate their phonological representations, and hence the deficit.

In both Friedman (1995) and Patterson et al. (1996), the grammatical morpheme deficit is linked to the inability to read nonwords and to the notion that grammatical morphemes have no strong semantic representation. The advantage of Friedman's proposal is that it is able to account for the variability in reading grammatical morphemes found among patients with a nonword reading deficit. Patterson et al.'s model lacks this flexibility, and distinctions between patients can only be made by referring to the severity of the deficits in phonological processing. The more severe the phonological deficit, the greater the impairment in both nonword reading and function word reading; the grammatical morpheme deficit varies together with the nonword reading deficit.

One of the consequences of causally connecting the grammatical morpheme deficit in phonological dyslexia with the negative features of grammatical morphemes (such as their having less dense associative networks or being of low imageability) is that the grammatical morpheme deficit becomes linked to deficits in reading abstract words. As grammatical morphemes and abstract words are on a continuum, both in terms of semanticity and imageability, in phonological dyslexia one would also expect some errors in reading abstract words. A second consequence is that the grammatical morpheme deficit becomes not an all-or-nothing phenomenon but a graded one. Grammatical morphemes are a mixed set; some fulfil only syntactic roles, and have no independent meaning (e.g., of in bottle of wine), whereas others, like spatial prepositions or personal pronouns, are both meaningful and imageable. According to the hypotheses of Friedman and Patterson et al., we would expect that in patients with a less than total deficit, function words that are more meaningful and more imageable would be read correctly whereas those fulfilling only syntactic roles would not (see Friederici, 1981, 1982, for a similar argument explaining selectivity in the omission of prepositions in agrammatism). 
Caramazza et al. (1985) considered the possibility that the grammatical morpheme deficit is an independent deficit, unrelated to the inability to read nonwords. Patients with impaired nonword reading and well-preserved grammatical morpheme reading provide an important source of evidence in favour of this hypothesis (e.g., Berndt et al., 1996; Caramazza et al., 1985; Funnell, 1983). There are, however, two potential problems with this type of evidence. One is that a patient whose nonword reading deficit dissociates from a grammatical morpheme deficit could be the type of phonological dyslexic, described by Friedman (1995), whose deficit derives from impairments to the phonological representations themselves (see also Shallice, 1988). The second is that, in some of the reported cases, the dissociation between word and nonword reading is not dramatic. For example, both $\mathrm{LB}$ and AG (Caramazza et al., 1985) read 70\% of nonwords and $98 \%$ of words (this is not true for Funnell's patient, WB, whose nonword reading was totally abolished). It is arguable, therefore, that the preservation of grammatical morpheme reading of $\mathrm{LB}$ and $A G$ is due to their mild impairment in nonword reading. If one of these two possibilities hold, dissociations between nonword and grammatical morpheme reading would not constitute counter-evidence to Patterson et al.'s interpretation of the grammatical morpheme deficit in phonological dyslexia. Nevertheless, the claim of Caramazza et al. remains important and the case of the patient that we report here could provide the missing empirical evidence.

Selective deficits of grammatical morphemes are not limited, of course, to deep and phonological dyslexic patients; the difficulties of Broca's aphasics with function words are well documented (e.g., Friederici, 1981, 1982; Goodenough, Zurif, \& Weintraub, 1977; Goodglass, 1976; Lapointe, 1985; Miceli, Silveri, Romani, \& Caramazza, 1989; Nespoulous et al., 1988; Saffran, Schwartz, \& Marin, 1980; Zurif, Green, Caramazza, \& Goodenough, 1976). Interestingly, there have been few links between the two lines of research despite the fact that at least some of the evidence concerning the grammatical morpheme impairment in Broca's aphasia comes from tasks involving the reading of individual function words (e.g., Andreewsky \& Seron, 1975; Friederici \& Schonle, 1980; Gardner \& Zurif, 1975), and there is considerable overlap in the two patient populations. In contrast to the dyslexia literature, in discussions of agrammatic Broca's aphasic patients there have been attempts to characterise function words by their distributional properties within sentences and by the syntactic roles they fulfil. Thus, the grammatical morpheme deficit, rather than being seen as a selective lexical deficit, has been considered to be a syntactic problem that has relevance at the sentence level only (e.g., Druks, 1991; Grodzinsky, 1988, 1990). Moreover, it has often been pointed out that information about the syntactic roles words fulfil within sentences is irrelevant for the production of individual lexical items (e.g., Caramazza, 1997; Friedman \& Grodzinsky, 1997; Miceli, Silveri, Villa, \& Caramazza, 1984). As acquired dyslexia has been mainly studied using single word paradigms, it is unsurprising that the grammatical status of function words has largely been overlooked. In contrast to these views, the objective of the present study is to show that individual words-both major lexical categories and function words-are equipped with a great deal of syntactic information that becomes activated whenever a word is used, even in single word tasks. Deficits associated with a particular grammatical category could be due to the loss or unavailability of such information.

Phonological dyslexic patients, whose reading of free-standing grammatical morphemes is impaired, tend also to have a deficit in reading affixed words. The two deficits usually appear together in individual patients and are considered to be functionally related (but see the case of Leonardo in Job \& Sartori, 1984). It has been argued that derivational morphology, marking a lexical process, is better preserved in agrammatism than inflectional morphology, which marks grammatical functions (e.g., De Bleser \& Bayer, 1988; Kolk, 1978; Miceli \& Caramazza, 1988). In studies of deep and phonological dyslexia, there were no empirical reasons for making a distinction, as no dissociation between the two types of affixation has ever been reported.

In the present paper we report the case of a patient whose ability to read nonwords is very 
limited although he can read most words, including very infrequent abstract words, very well. He has a serious deficit in reading function words and he makes many errors of affixation. We present a detailed case study of this patient because we believe that he provides a good example of the inability to read function words and nonwords. First we will show that, in the case of our patient, the impairment in reading grammatical morphemes is unrelated to the inability to read nonwords, and cannot be accounted for by their low semanticity or low imageability. Second we will argue that individual words carry a great deal of syntactic information. We will show that category and subcategory labels are just a shorthand for instructions about how to use the word up to the phrase level, and, therefore, function word deficits, even when manifested in single word reading tasks, could be characterised as syntactic deficits.

\section{CASE STUDY AND PRELIMINARY INVESTIGATIONS}

$\mathrm{MC}$ is a right-handed 74-year-old male who suffered a left-hemisphere embolic CVA in 1990 . He now has a right-sided hemiplegia. Prior to his stroke $\mathrm{MC}$ was a successful music impresario. The investigations reported here were carried out between 1995 and 2000. An assessment on the Boston Diagnostic Aphasia Examination (Goodglass \& Kaplan, 1972) showed a diagnostic profile similar to that of Broca's aphasia, although MC's articulatory agility is greater than would be expected of a Broca's patient, and his speech, though structurally ungrammatical, is not devoid of inflected and derived words or free-standing grammatical morphemes. His diagnostic profile on BDAE is in Appendix A. The PALPA aphasia assessment (Kay, Lesser, \& Coltheart, 1992) and other neuropsychological tests were initially used to examine MC's language and reading skills.

\section{Comprehension}

MC's comprehension in everyday contexts is very good. On the Pyramids and Palm Trees test
(Howard \& Patterson, 1992), he was 100\% correct on the three-pictures version and made only one error on the three-words version. He scored well ( $97 \%$ auditory and $94 \%$ written presentation) on the British Picture Vocabulary Scales (Dunn, Dunn, Whetton, \& Pintilie, 1982), and was $85 \%$ correct on the synonym judgement in PALPA 49. $\mathrm{He}$ is impaired, however, in the comprehension of syntactically complex reversible sentences (Froud $\&$ Druks, unpublished).

\section{Naming}

MC's naming ability is moderately impaired. In the Boston Naming Test (Kaplan, Goodglass, \& Weintraub, 1983), he named 48/60 (80\%) items correctly, in PALPA 54, 49/60 (82\%) items, and in an earlier version of the Object and Action Naming Battery (Druks \& Masterson, 2000), 108/140 (77\%) action and 129/140 (92\%) object pictures.

\section{Orthographic processing}

$\mathrm{MC}$ is able to carry out visual letter identification tasks. His identification of reversed letters, and matching of upper- and lower-case letters and multi-letter strings was errorless. In a visual lexical decision task with words and illegal letter strings (PALPA 21) he made no errors, and with legal strings as nonwords (PALPA 25), his score was 52/ 60 (87\%). Control subjects are almost perfect on this task. His errors were mainly false positives. MC's orthographic segmentation ability was tested by asking him to find words within words. The task contained 100 words of various length (e.g., sword, tangle, date, officer, vocalist, undersell) selected for the purposes of the present investigations. He performed extremely well, and often found more than one word embedded within a longer one, including function words (e.g., do, under, of, off). In contrast to his good orthographic processing of word stems, in a lexical decision task with nonwords that were constructed by illegal combination of real stems with real suffixes (PALPA 26), he made $15 / 30$ errors on nonwords but only $4 / 30$ errors on correctly suffixed words. No norms are available on this task but we 
may assume that control subjects would make only negligible numbers of errors.

\section{Phonological processing}

MC has no apparent articulatory deficits and phonological paraphasias are rare in his speech. On a rhyme judgement task with auditory presentation (PALPA 15) he scored $98 \%$ correct, and in a "same-different" discrimination task with nonwords (PALPA 1), 93\% (control subjects are 98\% correct). He managed to repeat correctly 20/30 (66\%) nonwords (PALPA 8). Six months later the task was readministered with similar results (22/ 30). On Glushko's (1979) list of short nonwords he repeated correctly 60/74 (81\%) items. In all nonword repetition tasks about half of $\mathrm{MC}$ 's errors are lexicalisations. His nonword repetition deficit seems to be largely due to production problems as his auditory lexical decision was relatively well preserved. At the very early stages of the study, having been presented with half of the items in PALPA 5, $\mathrm{MC}$ made three errors on nonwords, which is at the lower end of normal performance (controls make on average about 4 errors on the full list, with a standard deviation of 4.27). When the whole task was repeated about a year later, he made just one error. In a phonological segmentation and assembly task that was devised following the procedures used by Patterson and Marcel (1992), MC was presented with a spoken word and had to take the initial sound away (e.g., rage $\rightarrow$ age), or a specified sound had to be added to the beginning of a spoken word (e.g., ice $+n \rightarrow$ nice). This task was extremely difficult for $\mathrm{MC}$.

\section{Transcoding between orthography and phonology}

MC named only 5/52 (9\%) letters and sounded out only 6/52 (11\%) (PALPA 22), and could match only $11 / 26$ (42\%) letter sounds with their orthographic form (PALPA 23). Controls carry out these tasks almost perfectly. He performed poorly $(14 / 45,31 \%)$ on a phonological segmentation task in which he had to select the initial sound of a word or a nonword and match it with a written letter (PALPA 16). Control subjects perform with 98 and $95 \%$ accuracy. In a homophone decision task (PALPA 28) in which the patient has to decide if two visually presented words and nonwords sound the same or not, MC's performance was at chance (35/60, 58\%). He was also at chance $(32 / 60,53 \%)$ in a written rhyme judgement task (PALPA 15).

\section{Reading}

In reading words controlled for frequency and imageability (PALPA 31), MC read 30/40(75\%) of the high-frequency words, and 26/40 (65\%) of the low-frequency words, $\chi^{2}(1)=0.54$, n.s., and read $30 / 40$ high-imageability and 27/40 lowimageability words, $\chi^{2}=0.06$; n.s., correctly. Control participants read all words almost perfectly (mean for low imageabilility items is 19.52). The relatively high error rate in all categories is due to MC's tendency to add an indefinite article to some of the bare nouns. He made 11 such errors, mostly on high-imageability items (e.g., hand $\rightarrow$ a hand; axe $\rightarrow$ an axe). On the low-imageability items, most of his errors were visually related to the target (e.g., treason $\rightarrow$ treasure; clue $\rightarrow$ glue; analogy $\rightarrow$ analysis; irony $\rightarrow$ iron; gravity $\rightarrow$ gravy). The most striking feature of $M C^{\prime}$ 's reading, however, was his inability to read nonwords. He read only $2 / 24$ nonwords (PALPA 36). In most cases he produced a word visually similar to the target (e.g., cug $\rightarrow$ cup; lat $\rightarrow$ lattice; birl $\rightarrow$ girl).

\section{Writing}

MC's writing ability is severely limited and he is only able to copy words. In writing to dictation or in written picture naming, he writes nonwords often preceded by a determiner when naming objects (e.g., bed $\rightarrow$ a mettads; seahorse $\rightarrow$ a cenfirhl) and a personal pronoun when naming actions (e.g., a woman is crying $\rightarrow$ she sioches; a man is walking $\rightarrow$ he beiched; a woman is knitting $\rightarrow$ she toecher). Only occasionally is there a semantic or visual relationship to the target word (e.g., volcano $\rightarrow$ a etna; octopus $\rightarrow$ octorne). 


\section{Summary of the preliminary investigations}

MC's visual processing of orthographic material is intact and he is able to carry out easy phonological tasks that do not involve the transcoding of orthography into phonology. His nonword repetition is not perfect, but on Glushko's nonword list he managed to repeat $81 \%$ of the nonwords, a level of performance that, according to Friedman (1995), does not imply serious phonological impairments. Moreover, his auditory lexical decision performance is within the norm. However, he could not carry out more complex tasks such as phonological segmentation and assembly. This might indicate loss of phonological or, alternatively, metaphonological skills. He performed with ease a similar task in the visual modality (see orthographic processing). MC's ability to perform visual lexical decisions on stems indicates that his representations of morphologically simple words at the level of the visual input lexicon are intact. His poor lexical decisions on wrongly affixed strings could indicate that affixed words might be impaired at this early stage.

MC's ability to read single content words is relatively unimpaired. Word frequency and imageability did not significantly affect his performance although in PALPA 31 he made considerably more serious errors when reading lowimageability words. In later tests of reading lowimageability abstract words, however, MC's performance is not more impaired than in reading high-imageability words. Furthermore, the fact that the low-imageability words that he read later (see Reading grammatical morphemes and content words matched for imageability in Clinical Investigations) are considerably lower in imageability than the low-imageability words in PALPA 31 (190298 vs. 267-398) might also indicate that imageability is not the decisive factor for MC's somewhat impaired performance here.

MC cannot read nonwords and his reading of function words and morphologically complex words is severely impaired. This pattern of performance is similar to that of patients previously described as phonological dyslexics.
The purpose of the clinical investigations was to establish that $\mathrm{MC}$ is indeed a phonological dyslexic whose nonword reading is abolished and whose word reading is largely unimpaired apart from a deficit in reading grammatical morphemes. The word lists presented to him for reading probed the effects of lexicality, regularity, frequency, word length, grammatical class, concreteness, imageability, and morphological complexity on MC's reading ability.

\section{CLINICAL INVESTIGATIONS OF READING}

\section{The effects of lexicality, regularity, frequency, and word length}

\section{Lexicality}

Sixty-three nouns, verbs, and adjectives (e.g., leopard, brilliant, arrive) and nonwords taken from Shallice and Saffran (1986) were presented to MC to read. His reading of the words was good (almost all of his errors happened to be in reading adjectives). His reading of nonwords, however, was very poor, with errors involving production of visually related real words (e.g., friles $\rightarrow$ file; leabows $\rightarrow$ a bow).

\section{Regularity}

The effects of regularity were tested using three word lists (Coltheart, Besner, Jonasson, \& Davelaar, 1979; Glushko, 1979; Parkin, 1984). All three lists consisted of short (one or two syllable long) morphologically simple content words (there were only two morphologically complex words in Parkin's list, and one function word in Glushko's list). The difference between $M C$ 's reading of regular and irregular words was significant only in Coltheart's et al. list, $\chi^{2}(1)=6.37 ; p<.02$. Errors in all three lists were mostly inflectional or derivational, where MC added an affix to a morphologically simple word (e.g., aunt $\rightarrow$ auntie; mortgage $\rightarrow$ mortgages; prove $\rightarrow$ proven), visual (e.g., circuit $\rightarrow$ circus; subtle $\rightarrow$ substitute; palm $\rightarrow$ psalm), one semantic (bust $\rightarrow$ bosom) and one visual-andsemantic error (bitch $\rightarrow$ bike). 


\section{Word length}

Howard's (1991) list consists of four sublists of words of varying lengths. Seven of MC's errors were derivational, one was visual, one was semantic (motor $\rightarrow$ car) and in one case he added an indefinite article to a correctly read noun (spark $\rightarrow$ a spark). The number of errors in all sublists was similar.

\section{Frequency}

MC was presented with the 100 most frequent and the 100 least frequent words in English for reading (Francis \& Kucera, 1982). He read 14\% of the most frequent and $57 \%$ of the least frequent words. Although the results appear to show a reversed frequency effect, we do not suggest that this was a true test of frequency. We think that $\mathrm{MC}$ 's reading performance on this list is a demonstration that factors other than frequency have a strong effect on his reading. Seventy-four of the most frequent words were function words, and the least frequent words consisted of mostly derivationally complex abstract words. On the first list, his errors were mainly in reading function words (he read only 7 out of 74 function words). On the second list, most of his errors were derivational (e.g., pilgrimage $\rightarrow$ pilgrim). The number of words and nonwords correctly read in all the lists is in Table 1.

\section{The effects of grammatical class and concreteness}

Whereas in deep dyslexia reading is strongly affected by the grammatical class and the concreteness of words, in phonological dyslexia, grammatical class and concreteness effects are absent. Some phonological dyslexics, however, have a selective deficit in reading function words. To test the effects of grammatical class and concreteness, we compared $\mathrm{MC}$ 's reading of picturable nouns, verbs, abstract nouns and verbs, and of grammatical morphemes, and his reading frequency-matched abstract and concrete words.

\section{Reading of verbs and nouns from the Object and Action Naming Battery (Druks E' Masterson, 2000) and function words}

One hundred and forty-five picturable verbs and 132 nouns (in order to distinguish clearly between them, the verbs were presented in the infinitival form) and 119 function words (a few function words were presented more than once) were presented on cards in a random order during one testing session. The nouns and 132 of the verbs were matched for frequency (a full list of the function words in this and in the following task, together with MC's responses, is in Appendix B).

MC read 14 (12\%) function words correctly (what, via, why, since, by, it, some, and, how, with she,

Table 1. The number of words correctly read by $M C$ in lists testing the effects of lexicality, regularity, frequency, and word length

\begin{tabular}{|c|c|c|c|c|c|c|}
\hline & $\begin{array}{c}\text { Saffran E } \\
\text { Shallice }\end{array}$ & $\begin{array}{l}\text { Coltheart } \\
\text { et al. }\end{array}$ & Parkin & Glushko & Howard & $\begin{array}{c}\text { Francis \& } \\
\text { Kucera }\end{array}$ \\
\hline Words & $55 / 63$ & & & & & \\
\hline Nonwords & $6 / 126$ & & & $4 / 43$ & & \\
\hline Regular & & $36 / 39$ & $48 / 60$ & $31 / 43$ & & \\
\hline Irregular & & $26 / 39$ & $53 / 60$ & $31 / 43$ & & \\
\hline Most frequent & & & & & & $14 / 100$ \\
\hline Least frequent & & & & & & $57 / 100$ \\
\hline \multicolumn{7}{|l|}{ Length } \\
\hline 3 letters & & & & & $24 / 25$ & \\
\hline 5 letters & & & & & $21 / 25$ & \\
\hline 7 letters & & & & & $22 / 25$ & \\
\hline 9 letters & & & & & $23 / 25$ & \\
\hline
\end{tabular}


an, until, no). All his errors (apart from six no responses, and one derivational error) were withincategory substitution errors (i.e., other function words), though his responses did not preserve the part of speech of the function words. His most frequent incorrect function word response was before. There was no orthographic similarity, such as a shared initial letter or word length, between the target word and his response (e.g., everyone $\rightarrow$ before; all $\rightarrow$ for; itself $\rightarrow$ afterwards; they $\rightarrow$ and; every $\rightarrow$ after).

In contrast to his very impaired reading of function words, MC was able to read 140/145 (97\%) verbs and 127/132 (96\%) nouns correctly, though he often omitted to, the infinitival marker of the verbs, and added an indefinite article to the nouns. Apart from this type of error, he made the following incorrect responses in reading nouns: morphological errors (3, e.g., trousers $\rightarrow$ trouser), a semantic error (rectangle $\rightarrow$ triangle), a visual and derivational error (lightening $\rightarrow$ lights); and in reading verbs: nominalisation errors (2, e.g., to juggle $\rightarrow$ juggler), visual errors (2, e.g., to smash $\rightarrow$ splash), and a typical function word error (to follow $\rightarrow$ before or after).

\section{Reading of abstract nouns and verbs and function words}

Sixty abstract nouns and verbs were selected and presented for reading together with 60 function words. Most items in the noun list were morphologically complex (e.g., achievement, appreciation, benevolence, confidence, morality, safety). The verb list included items such as alleviate, bewilder, derogate, intend, and symbolise. MC correctly read 47 (78\%) nouns, 42 (70\%) verbs, and 5 (8\%) function words. His errors in reading nouns were derivational (5), visual (4), unrelated (3), and phonological (1); in reading verbs, derivational (11), visual (5), phonological (1), and no response (1). In the verb list, 7 of the derivational errors were nominalisations, and in the noun list, 5 were verbalisations. Due to experimenter's error, in both the verb and the noun lists there were eight verb/ noun ambiguous items (e.g., neglect, chance, wonder, care). As MC did not make mistakes on these items, it had no consequences for the results. All the errors on function words were within-category substitution errors.

\section{Reading concrete and abstract words matched for frequency}

MC was presented with 50 abstract and 50 concrete words selected from the MRC Psycholinguistic Database to read. Both the abstract and concrete words were morphologically simple and were matched pairwise for frequency (word frequencies ranged from 1 to 110). The concreteness ratings of the abstract words ranged between 231 and 300, and of the concrete words between 600 and 646 . MC made three errors (visual/semantic: birch $\rightarrow$ beech; and morphological: chicken $\rightarrow$ chick; phone $\rightarrow$ telephone) in reading the concrete words, and nine errors (derivational: admire $\rightarrow$ admirable; blame $\rightarrow$ blameless; tempt $\rightarrow$ temptation; vary $\rightarrow$ variable; visual: deceit $\rightarrow$ conceit; facility $\rightarrow$ faculty; jeopardy $\rightarrow$ leopard; stifle $\rightarrow$ rifle) in reading the abstract words. The difference is not significant, $\chi^{2}(1)=3.4$, n.s., and if we disregard derivational errors that can only be made on abstract words, the difference is further diminished, $\chi^{2}(1)=0.54$, n.s. The matched list is in Appendix C. Table 2 provides a quantitative summary of $\mathrm{MC}$ 's reading of abstract and concrete words and words of different grammatical categories.

Table 2. A summary of $M C$ 's reading of abstract and concrete words and of words of different grammatical categories

\begin{tabular}{|c|c|c|c|}
\hline & \multirow[b]{2}{*}{$N$} & \multicolumn{2}{|c|}{ Correct } \\
\hline & & No. & $\%$ \\
\hline \multicolumn{4}{|l|}{ Nouns } \\
\hline Concrete & 132 & 127 & 96 \\
\hline Abstract & 60 & 47 & $78 / 86^{\mathrm{a}}$ \\
\hline \multicolumn{4}{|l|}{ Verbs } \\
\hline Concrete & 145 & 140 & 97 \\
\hline Abstract & 60 & 42 & $70 / 85^{\mathrm{a}}$ \\
\hline \multicolumn{4}{|c|}{ Frequency matched } \\
\hline Concrete & 50 & 47 & 94 \\
\hline Abstract & 50 & 41 & $82 / 90^{\mathrm{a}}$ \\
\hline \multicolumn{4}{|c|}{$\begin{array}{l}\text { These lists contain many morphologically complex words } \\
\text { and words that have frequently used derived forms. MC } \\
\text { often omits, adds, or substitutes derivational affixes, an } \\
\text { error that is less likely to occur in concrete words. The } \\
\text { second numbers in the \% column give the percentage } \\
\text { correct if derivational errors are discounted. }\end{array}$} \\
\hline
\end{tabular}


Table 3. A summary of MC's reading of 179 function words in two reading lists

\begin{tabular}{|c|c|c|c|c|c|c|}
\hline \multirow{2}{*}{$\begin{array}{l}\text { Grammatical } \\
\text { class }\end{array}$} & \multicolumn{2}{|c|}{$N$} & \multicolumn{2}{|c|}{ Correct } & \multirow{2}{*}{$\begin{array}{c}\% \\
\text { Correct }\end{array}$} & \multirow[b]{2}{*}{ Type of errors } \\
\hline & List 1 & List 2 & List 1 & List 2 & & \\
\hline Determiner & 7 & 6 & 1 & 0 & 7.7 & FWS (11), n.r. (1) \\
\hline Pronouns & 8 & 11 & 2 & 0 & 11 & FWS (17) \\
\hline Preposition & 44 & 15 & 5 & 0 & 8.5 & FWS (49), n.r. (4) deriv. (1) \\
\hline Wh-words & 9 & 5 & 3 & 1 & 28.6 & FWS (10) \\
\hline Auxiliaries & 12 & 2 & 0 & 0 & 0 & FWS (14) \\
\hline Conjunction & 11 & 6 & 1 & 1 & 11.8 & FWS (15) \\
\hline Adverbs & 12 & 5 & 0 & 2 & 11.7 & FWS (15) \\
\hline Complementisers & 2 & 1 & 0 & 0 & 0 & FWS (2), n.r. (1) \\
\hline Quantifiers & 7 & 5 & 1 & 0 & 7.7 & FWS (11) \\
\hline Negation & 2 & 1 & 1 & 1 & 66.6 & FWS (1) \\
\hline Adjectives & 5 & 3 & 0 & 0 & 0 & FWS (8) \\
\hline Total & 119 & 60 & 14 & 5 & 10.6 & FWS (153), n.r. (6) deriv (1) \\
\hline
\end{tabular}

FWS = function word substitution; n.r. = no response.

Table 3 summarises MC's reading of function words and shows that the umbrella term of function word covers numerous different word classes. Among the function words, there were prepositions, determiners, pronouns, adverbials, quantifiers, auxiliaries, conjunctions, complementisers, adjectives, and wh-words. The classification presented in Table 3 (and Appendix B) is not the only possible one as many function words belong to more than one grammatical class.

In reading function words, MC's responses are invariably within-category substitutions. Out of 179 responses there were 19 correct responses, 6 no-responses, 1 derivational error (except $\rightarrow$ exceptional), and 153 other function words. While his default response is before (occurring 51 times), the following were also relatively frequent: at (21), after (19), and (14), for (8), because (5), it (4), as (4), and some occurred once (afterwards, an, to, up, down, underside, under, with, but, with, what, how). In the case of very few items there was a hint of either a visual or semantic link between the target and the response. The items in which visual similarity could be discerned are an $\rightarrow$ and; that $\rightarrow$ at; $I \rightarrow i t$; which $\rightarrow$ with; who $\rightarrow$ what; when $\rightarrow$ with; into $\rightarrow$ to; and items in which meaning affected the choice of the response were above $\rightarrow$ up; bebind $\rightarrow$ after; below $\rightarrow$ down; under $\rightarrow$ underside; who $\rightarrow$ what.

His correct (or incorrect) responding was not consistent. Only one target (what) was responded to correctly on two subsequent presentations and there was no indication that the semantically more salient function words were more likely to be produced that those with no meaning attached to them (see Appendix B). Finally, there is no indication in the data that the grammatical class of the function words had an effect on MC's success or failure in responding. Although in Table 3 we provide the percentage correct in each category, this should be assessed with caution because the number of items in each category was very different (ranging from 359). It would be a mistake, therefore, to conclude that wh-words or words of negation are wellpreserved islands among all other function words. It seems that MC's responses, in most cases, are due to random choices from the general pool of function words. The repetitious nature of his responding seems to indicate a tendency for perseveration.

\section{Effects of imageability}

It has often been suggested in the dyslexia literature, especially in relation to deep dyslexia, that high-imageability words are better preserved than low-imageability words. Furthermore, the imageability effect has been used to explain grammatical class effects. On this view, concrete nouns are read better than verbs because nouns tend to be more imageable than verbs; abstract nouns and function words are impaired because their 
imageability is low (e.g., Allport \& Funnell, 1981). In the following task we investigated the effects of imageability on MC's reading of words.

\section{Reading words of different grammatical categories rated for imageability}

Funnell (1983) provides imageability ratings for different word classes, including abstract and concrete nouns and verbs, adjectives, adverbs, quantifiers, pronouns, and prepositions. We presented Funnell's list $(N=280)$ to $\mathrm{MC}$ in a random order, to test the effects of imageability on his reading. Despite the fact that the imageability ratings of abstract nouns and function words are very similar, MC's reading of abstract nouns was far better than that of function words (see Table 4). In fact, his reading of abstract nouns was indistinguishable from his reading of concrete nouns, and all his errors were affixation errors (e.g., fund $\rightarrow$ funds, guilt $\rightarrow$ guilty) (similar results were obtained in the study reported earlier in which the abstract and concrete words were matched for frequency). His errors on function words were within-category substitutions. Most of his errors on verbs were affixation errors, one nominalisation error and five function word errors on so-called light verbs (know, make, put, want, and use). MC's similar performance on concrete and abstract nouns, and his very different level of performance on function words, indicate that his reading is not affected by imageability. There is a weakness, however, in

Table 4. MC's reading performance on lists controlled on imageability

\begin{tabular}{|c|c|c|c|}
\hline Word class & $N$ & $\begin{array}{c}\text { Mean } \\
\text { imageability }\end{array}$ & $\%$ correct \\
\hline \multicolumn{4}{|l|}{ Funnell's list } \\
\hline Concrete nouns & 111 & 5.8 & 85.6 \\
\hline Abstract nouns & 27 & 2.65 & 81.48 \\
\hline Adjectives & 58 & 4.5 & 87.9 \\
\hline Verbs & 29 & 3.76 & $62 / 79^{a}$ \\
\hline Function words & 61 & 2.07 & 11.4 \\
\hline \multicolumn{4}{|c|}{ Imageability matched list } \\
\hline Content words & 43 & & $72 / 86^{b}$ \\
\hline Function words & 43 & & 16 \\
\hline
\end{tabular}

Funnell's list (and in the way we used it) insofar that the number of items within the categories is unequal, and the imageability of function words and abstract words is not compared pairwise only on the basis of mean imageability, within categories. In order to demonstrate more convincingly that MC's reading is not affected by imageability, an additional reading list was prepared.

\section{Reading grammatical morphemes and content words matched for imageability}

Forty-three grammatical morphemes and 43 morphologically simple content words (mainly abstract words) that could be matched pairwise on imageablity were selected from the MRC Psycholinguistic Database and presented to MC for reading (e.g., an - gybe; but-amity; the - circumstance; than - stipend; for - panoply). Imageability ratings ranged between 190 and 298. MC read 7/43 (16\%) function words and 31/43 (72\%) content words correctly, $\chi^{2}(1)=27.16, p<.001$. All except three visual errors $($ since $\rightarrow$ sincere; ever $\rightarrow$ even; there $\rightarrow$ think) in reading function words were withincategory substitutions. Despite the fact that all the content words in the list were morphologically simple, MC made six derivational errors by adding to the stem a derivational affix (e.g., consist $\rightarrow$ consistent; concept $\rightarrow$ conception; consider $\rightarrow$ consideration), five visual errors (e.g., abstruse $\rightarrow$ abstract; extent $\rightarrow$ extenuate; latter $\rightarrow$ lattice) and one visualsemantic error (synod $\rightarrow$ synagogue). As the function words and the content words were matched for imageability, the considerable discrepancy between MC's reading them is a strong demonstration that imageability is not a contributing factor to his failure in reading function words. The low imageability (and low frequency) of the content words did not seriously impair their reading by MC. This is true especially if we take into consideration that six of his errors were derivational errors that are, in fact, functional (the matched list is in Appendix D). Table 4 presents MC's reading performance on the different word classes in Funnell's list together with the mean imageability ratings of the words belonging to that class, and on the imageability matched content words and grammatical morphemes. 


\section{Effects of morphological complexity}

\section{Reading words and nonwords, and legally and illegally affixed words (Shallice E Saffran, 1986)}

The list consists of 63 stems, 63 stems + legal derivational and inflectional affixes (e.g., kettles, jealously, organises), 63 stems + illegal affixes (e.g., windowing, attractived, galloply), and 126 nonwords.

MC's reading of the stems and of nonwords was reported earlier. Here we concentrate on his reading of the legally and illegally affixed words. $\mathrm{He}$ could not read any of the illegally affixed words (0/ $63)$ and only a few of the legally affixed ones (5/63). His most frequent error was the omission of the (legal or illegal) affix.

\section{Reading derived and pseudoderived words}

Errors in reading morphologically complex words are compatible with three types of interpretation. One is that they are truly morphological errors that reflect deficits in processing morphologically complex words, and may indicate that affixes have separable representations in the lexicon. However, these errors could also be thought of as semantic or visual as affixation errors are always semantically related and visually similar to the target. Some investigators believe that it is parsimonious, if a patient makes both morphological and semantic/visual errors, to assume just one deficit (e.g., Funnell, 1987). As MC often made visual errors, to test whether his errors on morphologically complex words were visual errors, we presented him with 32 derived words (e.g., machinery, painter, and friendly) and 32 stems in which the final string of letters are accidentally identical to a derivational affix (e.g., fairy, flower, tally) for reading. The affixed and pseudoaffixed words, and the stems and pseudostems, were matched for imageability (the list of items was taken from Funnell, 1987). MC $\operatorname{read} 22 / 32(68 \%)$ of the stems correctly and 13/32 $(41 \%)$ of the derived words, $\chi^{2}(1)=4.04 ; p<.05$. His most common error (16) on the derived words was the omission or substitution of the derivational affix. On the pseudoaffixed words he made only four "morphological" errors.
MC's reading of derived words is significantly more impaired than his reading of pseudoaffixed words, showing that he treats monomorphemic words differently from morphologically complex words and that his affixation errors are determined by the morphological structure of the word, rather than its visual similarity to the target. MC's reading performance differed from the performance of CJ, who was equally impaired on affixed and pseudoaffixed words, but was similar to that of JG, who made more errors of affixation on affixed words (Funnell, 1987).

\section{Reading derived and inflected words}

Seventy-five words with a variety of derivational affixes (e.g., homely, powerless, gracious, magnetic, and employment) and 75 inflected words ( 15 plural nouns, 15 adjectives such as greater, 153 rd-person verbs, 15 past tense verbs, and 15 present participles) mixed with morphologically simple words taken from other lists were presented to $\mathrm{MC}$ for reading. He managed to read correctly $35 / 75$ (47\%) derived words and 30/75 (40\%) of inflected words. All his errors, apart from one stem error in the inflected list, and three stem errors in the derived list, were of affixation and were well formed. Among the inflected forms, $\mathrm{MC}$ made no errors in reading plural nouns and read correctly $11 / 15$ present participles. The present participle was also his most frequently used substituted form. His reading of all other categories was very poor.

There were roughly equal numbers of omission and substitution errors. Among the derived words there were 15 omissions, 17 substitutions, and 5 additions of an affix, and among the inflected words, 17 omissions and 12 substitutions but no addition errors. MC's reading of derived and inflected words is considerably better (about 45\%) than his reading of free-standing grammatical morphemes (about 12\%). The difference is due probably to the stem providing information about the affixes permissible in a given context and greatly reducing the range of well-formed possibilities. 


\section{Summary of clinical investigations}

MC's reading conforms to the pattern of reading in phonological dyslexia. There is a strong dissociation between word and nonword reading and, although more errors were made on the irregular than on the regular words in Coltheart at al.'s corpus, this difference disappeared completely in Parkin's and Glushko's lists. Without counting the 100 most frequent words, as these consisted mainly of function words, MC read without error 1093/ $1312(83 \%)$ of all the words (results reported in Tables 1, 2, and 4). Some of these lists were mixed lists that contained function words and morphologically complex words. MC's errors on words were mainly derivational, inflectional, and visual. Very few (8) semantic errors were made. His reading is not affected by word length and he is not impaired at reading very infrequent words.

A theoretically pure case of phonological dyslexia would be a patient who can read all words and no nonwords. Reported cases of phonological dyslexic patients, however, tend to deviate to various degrees from the pure case. In some patients word reading is also somewhat impaired (most reported errors being function word substitutions, affixation errors, and visual errors) and, in the majority of patients, nonword reading is preserved to some degree. As it is known that nonword reading is less accurate than word reading even in normal readers (Masterson, 1985), evidence of a large difference between word and nonword reading is needed in order to make theoretical claims (Patterson, 1982; Shallice, 1988). We believe that $\mathrm{MC}$ is one of the few cases of phonological dyslexia whose nonword reading is (almost) totally abolished. The magnitude of MC's deficit in nonword reading is comparable only to that ofWB (Funnell, 1983), who did not manage to read any nonwords. WB, however, was tested only on 20 nonwords, while MC's result is based on 256 nonwords (PALPA, Glushko's list, and Shallice \& Saffran's 1986 list). Table 5 shows the percentage of words and nonwords read by reported cases of phonological dyslexic patients. It can be seen that the range of abilities, especially in nonword reading, is wide, ranging from $0 \%$ to $80 \%$, with most patients being able to read around $50 \%$ of the items.
Table 5. The percentage of words and non words read by $M C$ and by other phonological dyslexic patients

\begin{tabular}{llcc}
\hline & & $\begin{array}{c}\text { Word } \\
\text { reading } \\
\text { (\% correct) }\end{array}$ & $\begin{array}{c}\text { Nonword } \\
\text { reading } \\
\text { (\% correct) }\end{array}$ \\
\hline Ratient & (Beauvois \& Derouesne, 1979) & $80 \%$ & $10 \%$ \\
JA & (Derouesne \& Beauvois, 1979) & $100 \%$ & $55 \%$ \\
PH & (Derouesne \& Beauvois, 1979) & $100 \%$ & $80 \%$ \\
MF & (Derouesne \& Beauvois, 1979) & $100 \%$ & $42 \%$ \\
RG & (Derouesne \& Beauvois, 1979) & $100 \%$ & $25 \%$ \\
AM & (Patterson, 1982) & $86 \%$ & $0-37 \%$ \\
WB & (Funnell, 1983) & $90 \%$ & $0 \%$ \\
BTT & (Shallice \& Warrington, 1980) & $90 \%$ & $50 \%$ \\
LB & (Derouesne \& Beauvois, 1985) & $95 \%$ & $48 \%$ \\
JW & (Manning \& Warrington, 1996) & $98 \%$ & $53 \%$ \\
MRF & (Manning \& Warrington, 1996) & $96 \%$ & $50 \%$ \\
GRN & (Shallice \& Warrington, 1980) & $98 \%$ & $8 \%$ \\
ML & (Lesch \& Martin, 1998) & $100 \%$ & $38 \%$ \\
MC & & $71-96 \%$ & $5 \%$ \\
\hline
\end{tabular}

MC's ability to read uninflected verbs and nouns is relatively well preserved, and no differences were found between his performance in reading long lists of verbs and nouns. He often makes derivational errors when the verbs and nouns are morphologically complex. Equally often, when this is possible, he will add a derivational morpheme to a bare verb or noun, a determiner to a noun, and -ing to a verb. In only one list (see Table 4) does he make more than his usual number of errors in reading verbs (38\%). The number of errors is reduced to $21 \%$, however, when morphological errors (involving the adding of -ing) are discounted. The fact that $\mathrm{MC}$ is equally likely to make nominalisation and verbalisation errors might also indicate that he is not more impaired in reading verbs than nouns.

MC's reading of abstract words is relatively well preserved, especially if derivational errors are discounted. His equally well-preserved reading of abstract and concrete words clearly differentiates him from deep dyslexic patients who "all read concrete words five times better than abstract ones" (Shallice \& Plaut, 1992, p. 253). Moreover, his comparable performance on the frequencymatched abstract and concrete words shows that the relatively low semanticity of abstract words (in comparison to concrete words) did not have an effect on his reading. See Shallice and Plaut (1992) 
for the argument that concrete words have more specific and detailed meaning (Saffran, Schwartz, \&Marin, 1979), that more predicates can be generated about them (Jones, 1985), and that they require more semantic features (e.g., Shallice \& Plaut, 1992) than abstract words.

His reading of function words, however, is very impaired. MC could not read more than $8-12 \%$ of large lists of function words, whereas AM (Patterson, 1982), a patient similar to MC in many respects, read 78\%. Almost all $\mathrm{MC}$ 's errors were within-category substitution errors (his default response was before) that, with few exceptions, did not bear visual or semantic resemblance to the target. His making of within-category substitutions suggests that he is capable of distinguishing between function words and both other word classes (where he makes visual errors) and nonwords (where he makes visually similar lexicalisation errors).

$\mathrm{MC}$ is also impaired in reading affixed words, and his poor reading of derived and inflected words appears to be morphologically determined. His level of impairment in reading inflected and derived words is similar and he makes both omission and substitution errors in both types of words in approximately equal numbers. Among the inflections, plural nouns and present participles are better preserved than tense and agreement markers on verbs.

\section{EXPERIMENTAL INVESTIGATIONS}

The objective of the experimental investigations was to find the functional locus of $\mathrm{MC}^{\prime}$ 's serious deficit in reading free and bound grammatical morphemes. The question we will ask is whether his impairment is evident in output tasks only, or also in word recognition and comprehension tasks.

\section{Written word recognition tasks}

Our objective in the first section of the experimental studies was to explore the intactness of representations within the orthographic input lexicon by using the lexical decision task. From the prelimi- nary studies we know that $\mathrm{MC}$ is able to carry out lexical decisions on morphologically simple content words and nonwords derived from them, but not with legally and illegally combined stems and affixes. In task 1 we explored further MC's problem in recognising incorrectly affixed real words, and in task 2, we tested his ability to carry out a lexical decision task with free-standing grammatical morphemes.

\section{Task 1: A lexical decision task containing stems and affixed stems and illegally affixed stems (Shallice $\Xi^{\circ}$ Saffran, 1986)}

The task consists of stems (e.g., leopard, brilliant, arrive), stems + legal derivational and inflectional affixes (e.g., kettles, jealously, organises), stems + illegal affixes (e.g., windowing, attractived, galloply) and nonword filler items (e.g., perfently, monerful, fancils). There were 19 verb stems (due to experimental error), 21 noun stems, and 21 adjective stems. The results are given in Table 6.

MC performed normally on nouns, verbs, and adjectives in stem and legally affixed forms. His performance, however, dropped sharply on illegally inflected words. MC accepted one third of the illegally affixed adjectives, two thirds of the illegally affixed nouns, and most of the illegally affixed verbs. In the light of his poor performance with the illegally affixed words, it is doubtful that his judgements on the legally affixed words are based on intact orthographic analysis. It is more likely that he

Table 6. $M C$ 's performance on the lexical decision task (Shallice E Saffran, 1986)

\begin{tabular}{llcr}
\hline & \multicolumn{1}{c}{ Examples } & \% correct & $N$ \\
\hline Nouns & & & \\
Stem & leopard, jacket & 100 & 21 \\
Legal affix & kettles, forests & 100 & 21 \\
Illegal affix & scarfing, terracest & 33.3 & 21 \\
Verbs & & & \\
Stem & arrive, invade & 100 & 19 \\
Legal affix & invited, prepares & 100 & 21 \\
Illegal affix & admirely, inventest & 14.3 & 21 \\
Adjectives & & & \\
Stem & brilliant, terrible & 100 & 21 \\
Legal affix & hungrier, strangest & 100 & 21 \\
Illegal affix & tighting, polites & 66.6 & 21 \\
Nonwords & parfently, frile & 87.3 & 126 \\
\hline
\end{tabular}


accepts legally affixed words as words because both the stem and the affix in isolation are familiar to him. His inability to reject the illegally affixed words indicates that he is unable to judge the correctness of the combination of stem and affix. AM (Patterson, 1982) and Leonardo (Job \& Sartori, 1984) performed similarly.

\section{Task 2: Lexical decision with function words and nonwords created by changing one letter in a \\ function word}

The task consists of 93 function words, 93 nonwords created by changing one letter in a function word (e.g., betweed, anynody, fron), 60 content words, and 60 nonwords created from the content words. MC's performance was equally good on all items: $98 \%$ on the function words, $98 \%$ on the nonwords created from the function words, $100 \%$ on the content words and $92 \%$ on the nonwords created from the content words.

\section{Summary of the written word recognition tasks with} function words and morphologically complex words A written lexical decision task is a purely visual task that taps the intactness of the orthographic input lexicon. We found that $\mathrm{MC}$ can reliably distinguish between free-standing function words and nonwords created from them. His performance on morphologically complex words and illegally affixed strings is different, however. He reliably accepts legal combinations as words, but he has a problem in rejecting illegally affixed stems, presumably because both the stem and the affix appear familiar. The evidence from the lexical decision tasks suggest that the representations of morphemes in the visual input lexicon, including those of grammatical morphemes and of bound morphemes in isolation, is well preserved. The evidence from the lexical decision task with morphologically complex words also suggests that stem and affix have separable representations at this level.

\section{The comprehension of written free and bound grammatical morphemes}

It has often been claimed that function words have little meaning attached to them, and this is why they are so vulnerable in aphasia. However, function words are a mixed category of words: some of them indeed have no meaning at all, such as those prepositions that do not assign a thematic role, only case (e.g., proud of John). Others, such as spatial prepositions, although poorer in semantic features than concrete nouns, do have discernible meaning. In this part of the experimental studies we investigated MC's comprehension of those grammatical morphemes and derivational and inflectional affixation that we could find a way to test.

\section{Task 3: The comprehension of spatial prepositions (a)}

In the first experiment, the experimenter created 16 different spatial situations (using real objects) that required the use of prepositions to describe them, such as in, on, below, around, opposite, against, from, etc. For each item MC was given a list of four written prepositions and was asked to indicate which of them best described the situation. For example:

Situation:

coin placed inside glass

List of prepositions: in under on up

MC was correct on 14/16 (87.5\%) test items (he failed to respond to the situations involving to and with). In contrast, he could only read two of the prepositions (down and against).

\section{Task 4: The comprehension of spatial prepositions (b)}

The second experiment was a word-picture matching task (Druks, 1991) consisting of 12 sets of 4 pictures, with each set depicting 2 objects in 4 different spatial relations to each other. For example, one set showed the moon under, over, behind, and beside a cloud; and a second one showed shoes in a wardrobe, beside a wardrobe, on (top of) a wardrobe, and under a wardrobe. The prepositions were written on separate cards, and the pictures were presented on four separate occasions so that all four prepositions could be targeted. There were, thus, a total of 48 test items. MC was asked to select the picture that matched the word written on the card.

MC made only 4 (8\%) errors on this task, indicating that he is able to access the meaning of indi- 
vidually presented written spatial prepositions that he cannot read.

\section{Task 5: The comprehension of other grammatical morphemes (a)}

In the first task we used pairs of function words (e.g., here - there; who - what; all - nothing; these those). In order to generate more data, for each pair of words, six pictures were drawn containing different objects: trees, houses, apples, etc. For here and there, for example, one item contained a large tree (here) and a smaller tree in the distance (there); for who and what, one item contained a boy (who) and an apple (what). Both target words were written on the picture of the two items and $\mathrm{MC}$ was asked to link the words with the appropriate pictures. There were 80 items in the task. MC carried out the task with confidence and made only a few errors (7\%), most of them on nothing - all, for which our pictures proved ambiguous.

\section{Task 6: The comprehension of other grammatical morphemes (b)}

Our second task was based on an idea of Funnell and Allport (1987) and it tested the comprehension of the function words without, only, just, and, and not. Six sets of three pictures showing pairs of objects together and individually were drawn. For example, one set showed a pen, a book, and a pen and a book together. The three pictures constituted an item and $\mathrm{MC}$ was asked to match the following written phrases presented to him individually and in a random order to one of the three pictures:

$\begin{array}{lll}\begin{array}{l}\text { pen and book } \\ \text { pen without }\end{array} & \begin{array}{l}\text { book and pen } \\ \text { book without }\end{array} & \begin{array}{l}\text { only book } \\ \text { only pen }\end{array} \\ \text { book } & \text { pen } & \\ \text { just pen } & \text { just book } & \text { not pen } \\ \text { not book } & & \end{array}$

The 6 sets each with 10 target words amounted to 60 items. MC was correct on $95 \%$ of the items.

\section{Task 7: The comprehension (and reading) of derivationally complex words (a)}

Thirty-six pairs of derivationally related words in which one of the words denoted a person were selected (the idea for this experiment is derived from Funnell, 1987). In 12 pairs both words had a suffix, $-e r$ for the person and -ing for naming the action (e.g., teaching - teacher), in 11 pairs the word denoting the person was a stem without a suffix and the second word had various suffixes and meanings (e.g., poet, poetry; vicar, vicarage), and in 13 pairs the person's label had various suffixes and the second word was a stem (e.g., musician, music; scientist, science). The pairs of words were presented in a random order and MC was asked to select the word that denoted the name of a person. He carried out the task without error. Two weeks later $\mathrm{MC}$ was asked to read all the 72 words. His reading of the stems was errorless but he made many errors on morphologically complex words. Among them he made 11/25 (44\%) derivational errors on the morphologically complex words that designated a person. The results show that MC has intact comprehension for the meaning expressed by a wide range of derivational affixation that he makes many errors in reading.

\section{Task 8: The comprehension of derivationally complex words (b)}

In a second test of derivational morphology, MC's understanding of affixation denoting gender was investigated. He was presented with 56 written words, half of which designated a masculine, and half a feminine, being. The list contained 13 pairs of stems in which the gender distinction is expressed lexically (e.g., aunt, uncle; spinster, bachelor), 12 pairs in which the gender distinction is expressed morphologically by a suffix, marking the word designating the female (e.g., priest, priestess; emperor, empress), and 3 pairs of pronouns (him, her; he, she; his, hers). The words were presented to MC singly and in a random order and he was asked to sort them according to their gender. He did not make mistakes in this task, demonstrating good comprehension of written gender specific content words, affixation that denotes gender, and also gender-specific personal pronouns.

\section{Task 9: The comprehension of inflected verbs (a)}

We constructed 60 sentence frames in which a verb was missing. In 15 sentences an obligatorily $3 \mathrm{rd}$ person singular verb was missing (e.g., When 
Thomas is in a hurry, he constantly asks what the time is); in 15 sentences a past tense verb (e.g., Last year my friend from Australia was in Europe. She stayed with me for a week); in 15 sentences a 1st person singular present tense verb (e.g., When I am sad I listen to music); and in 15 sentences 3 rd person plural present tense verb was missing (e.g., Some students are very hardworking, and always attend all their lectures). The sentence frame was read out to $\mathrm{MC}$, and he could also see the written sentence with the gap for the missing verb clearly marked. Below the sentence was the target verb in four forms: bare form, 3rd person singular, past tense, and the -ing form. $\mathrm{MC}$ was asked to mark the verb that best completed the sentence.

MC made 13 correct choices (6/15 on sentences that required $3 \mathrm{rd}$ person verbs, $6 / 15$ on sentences that required past tense verbs, $1 / 15$ on those that required the 1 st person singular form). Eleven neurologically unimpaired participants made on average one error each on the 60-item task. This task is clearly very difficult for $\mathrm{MC}$ and his performance is at chance level. His performance is somewhat better, but still poor, on sentences in which tense is morphologically marked (3rd person present tense and past tense). He selected the bare verb form only twice in the whole set of sentences.

It is possible that that MC's poor performance was due to the specific demands of the task rather than his inability to process verb inflections. The sentences were read aloud to him and, especially if he tries to fill the missing verb subvocally, the task involves transcoding from phonology to orthography, something that MC is unable to do (see Preliminary Investigations). We therefore designed a second, purely visual, task to test MC's comprehension of verb (and noun) inflections.

\section{Task 10: The comprehension of inflected verbs and nouns (b)}

For the following tasks 15 unambiguous verbs (that do not have a noun reading), 15 unambiguous nouns with regular plurals, and 15 other verbs that have a regular past tense were selected. The experiment consisted of 10 tasks and was carried out during 5 sessions separated by at least a week. The tasks were carefully explained to $\mathrm{MC}$, following which he was able to produce orally correct examples of the word forms he had to select from the written array. In some arrays, $\mathrm{MC}$ was presented with four types of words (60 words), and in others two (30 words), and was asked to pick out one type. The order of presentation of the tasks in the actual experiment was different from the order given here.

Tasks 1,2, and 3 involved the selection of nouns. In task 1 , he was presented with singular and plural nouns and with 3rd-person singular and bare stem verbs and was asked to pick out the singular nouns. $\mathrm{He}$ carried out the task with no errors. In task 2 , he was presented with the same array as in task 1 , and was asked to pick out plural nouns; again he made no errors. In a final task that involved nouns, he was presented with plural nouns and 3rd-person verbs and was asked to sort them into things and actions. $M C$ made two errors.

There were five tasks that involved different forms of verbs. In tasks 4, 5, 6, and 7 the distinction to be made was between the bare stem and the present tense 3rd-person singular form. In task 4, the array consisted of singular and plural nouns, bare stem and $3 \mathrm{rd}$-person verbs, and $\mathrm{MC}$ was asked to pick the 3 rd-person verbs. He never selected a noun; however, he picked out 10 bare stem verbs and missed $83 \mathrm{rd}$-person verbs. In task 5 , he had again to select $3 \mathrm{rd}$-person verbs from a smaller array of bare stems and 3rd-person verbs. In this condition he made only three incorrect selections and missed one item.

In task 6 he was presented with bare stem and 3rd-person present tense verbs and was asked to select all verbs that can be used with "I." He made nine correct selections and missed six items. When this task was repeated in a different session, he made two wrong selections and missed three items. In task 7, the array consisted of singular and plural nouns and bare stem and 3rd-person verbs to select verbs that can be used with "they." Despite the fact that prior to the sorting task he was able orally to give many examples of correctly used verbs, in the sorting task he selected wrongly 14 3rd-person verbs. The task was repeated in a different testing session with similar results.

In tasks 8, 9, and $10 \mathrm{MC}$ had to select past tense verbs from different arrays. In task 8 , the array con- 
sisted of plural nouns, bare stem verbs, 3rd-person present tense and past tense verbs. $\mathrm{MC}$ made no errors. We were intrigued by MC's errorless performance involving past tense verbs and, therefore we repeated the task twice during different testing sessions in a different form. In task 9, he was presented with all the verb forms (bare form, 3rd-person present, and past tense) from which to select the past tense. The task was repeated twice in different testing sessions. On the first occasion, he included one 3rd-person verb, and missed two past tense verbs, and on the second occasion, he included three wrong items. Finally, in task 10, he was presented with past tense and 3 rd-person present tense verbs and was asked to sort them into past and present tense verbs. He made no errors.

\section{Summary of the comprebension (and production) of free and bound grammatical morphemes}

MC's comprehension of the "meaning" of grammatical morphemes is considerably better than his ability to read them. We have evidence that $\mathrm{MC}$ understands the meaning of written spatial prepositions, personal pronouns, some determiners, and some quantifiers. His performance on these comprehension tasks was, though not perfect, impressive. Two neurologically intact age-matched control subjects made no errors on tasks 3, 5, and 6 .

The evidence for relatively well-preserved comprehension of items that $\mathrm{MC}$ can no longer read aloud is even more interesting in relation to bound grammatical morphemes. We tested the comprehension of agentive derivational affixes, such as $-e r$, -ist, gender marking derivational affixation, and of inflectional affixes attached to nouns and verbs.

MC's choices of the words that designated persons in the sorting task were confident and errorless, despite the fact that he had to make his selection from words with a variety of affixes. The second task required sorting according to gender. Affixations marking gender are inflectional in languages that involve gender in agreement relations with verbs. In English, however, there is no gender agreement between subjects and verbs. Gender affixation in English, therefore, seems to be a purely semantic feature that is derivational in nature (see also Radford, 1997). MC's sorting, similarly to the previous task, was errorless not only for the stems and the derived words but also for the few personal pronouns in English that are gender specific.

MC's understanding of inflectional affixation is more complex. He has no problems in distinguishing between singular and plural nouns, or between plural nouns and 3rd-person present tense verbs (the latter task can be carried out, of course, by attending only to the stems). However, his performance involving inflected verbs is considerably less reliable. In the sentence completion task (which may involve recoding phonology to orthography) he was at chance level. In the sorting task, his performance was relativelywell preserved for past tense verbs but poor for the rest of the verb forms.

Thus evidence from the last set of experiments suggests that $\mathrm{MC}$ 's deficit in reading free-standing grammatical morphemes and derivationally affixed words is an output-only deficit. He can recognise them, and we have evidence that, when this is testable, he can understand their meaning. This is also true for the plural inflectional marker. His deficit in relation to verb inflections is less clear. It seems that he cannot reliably distinguish between the written forms of inflected verbs and cannot interpret their tense and agreement features. It is possible, however, that for MC tense features are better preserved than agreement features.

\section{Task 11: Spontaneous speech, text reading, and single word reading-a comparison}

It has been suggested that some (deep) dyslexic patients whose reading of single function words is very impaired are, nevertheless, capable of using function words with relative ease in spontaneous speech (Coltheart, 1987), and even their reading of function words improved when these were presented within the context of other words in short texts (Silverberg et al., 1998). To find out if this was true for $\mathrm{MC}$ we compared his speech, text reading, and single word reading using the same materials. MC told the story of the ballet Sleeping Beauty. We analysed his first 158 narrative words using the Quantitative Production Analysis of Berndt, Wayland, Rochon, Saffran, and Schwartz (2000). In our analysis we concentrated on the availability of free and bound function words and verbs. We 
then re-wrote MC's narrative (using 149 words) by employing minimal corrections to create a grammatical sequence, and presented it to him to read in a different session about 6 weeks later (MC's tale of Sleeping Beauty is in Appendix E). Table 7 gives a quantitative summary of $\mathrm{MC}$ 's spontaneous speech, text reading, and the mean scores derived from the narratives of 12 normal and 29 nonfluent aphasic patients for comparison, taken from Berndt et al. (2000). It should be noted that Berndt et al's, analysis registers errors only in the row of the number of well-formed utterances. In other items it counts the number of times a particular category occurs in an obligatory context irrespective of whether it is correct or not. Within-category substitution errors thus are overlooked.

As can be seen from the table, MC's rate of speech is at the upper range of the aphasic patients. His utterance length is shorter than that of normal controls but longer than that of the average patient. Despite the fact that the number of verbs, verb inflections, and free-standing grammatical morphemes in MC's speech is close to normal, only half of his utterances were well formed in their entirety, a proportion similar to that of other nonfluent patients. The quantitative analysis shows that MC does not omit grammatical morphemes from his speech. There are, however, several substitution errors (e.g., has $\rightarrow$ is; were $\rightarrow$ was; fairies $\rightarrow$ fairy; later $\rightarrow$ ago) and other mistakes such as omission of content words and phrases (e.g., turn in took a turn; when she touched it) and ungrammatical sentence structuring, especially when the ideas to be expressed are complex (such as the idea of the curse that is to take effect later and on the condition that Sleeping Beauty will touch the spindle) and require the use of complex tense and structure. Simpler ideas, on the other hand, are often well expressed in grammatical utterances (e.g., at sixteen the child was a lovely girl; cursed the spindle; the wicked fairy cast the spell).

MC's treatment of grammatical morphemes in spontaneous speech is very different from what we are familiar with in his reading of them as single words. In reading single words, he invariably makes function word errors that are unrelated in form, meaning, or function to the target. His substitution errors in spontaneous speech, however, are related in meaning and/or grammatical function to the intended target.

MC's reading (see Table 7) is faster than his speech, his utterances are longer, and the proportion of well-formed sentences is somewhat higher. He makes, however, many substitution errors (e.g., were $\rightarrow$ are; arrived $\rightarrow$ arrives; a $\rightarrow$ the; had $\rightarrow$ has), some omissions of grammatical morphemes (e.g., all, but, when, other), and many omissions and substitutions of content words, phrases, and even whole sentences (e.g., omissions: there was a christening; took a turn to point; the age of; little; substitutions: king and queen $\rightarrow$ prince and princess; baby $\rightarrow$ princess). His reading, thus, is highly inaccurate but,

Table 7. A quantitative analysis of $M C$ 's speech and text reading in comparison to normal controls and nonfluent aphasic patients

\begin{tabular}{lcccc}
\hline Measure & Normal controls & Nonfluent patients & MC's speech & MC's reading \\
\hline Speech rate $^{\mathrm{a}}$ & 160.82 & 39.01 & 45.80 & 63.60 \\
Length of utterance $^{\mathrm{b}}$ & 8.17 & 3.57 & 6.00 & 8.00 \\
Well-formed sentences $^{c}$ & 0.95 & 0.56 & 0.57 & 0.75 \\
Closed class $^{c}$ & 0.54 & 0.41 & 0.66 & 0.58 \\
Determiners $^{c}$ & 0.99 & 0.65 & 0.91 & 0.92 \\
Pronouns $^{c}$ & 0.41 & 0.25 & 0.44 & 0.19 \\
Verbs $^{c}$ & 0.48 & 0.37 & 0.55 & 0.40 \\
Verb inflections $^{c}$ & 0.92 & 0.56 & 1.00 & 1.00 \\
Auxiliaries $^{c}$ & 1.26 & 0.78 & 0.92 & 1.00 \\
\hline
\end{tabular}

${ }^{\mathrm{a}}$ Mean number of words per minute.

${ }^{\mathrm{b}}$ Median length of utterance.

${ }^{\mathrm{c}}$ Proportion in obligatory contexts. 
like his speech, is not devoid of grammatical morphemes. In fact, his reading is very similar to his speech. Compare, for example, MC's speech: In the gallery was lots offairies which dancing. Each one took to point to the baby and... like to give a present. The other thing is the wicked fairy, the curse, which is a pin ... or a bodkin; with MC's reading: In the gallery there are lots offairies. Each one of them to to baby and to a present. The wicked fairy ... cursed the spindle and said that would be baby should be touched to die (the reading text and the transcript of $\mathrm{MC}^{\prime}$ 's reading are in Appendix F).

Finally, in order to maximise the power of comparison, during a separate session 3 weeks later we asked MC to read 111 single words taken from the text he had read previously. The words were presented in a random order and inter-mixed with a large number of words from an unrelated list. Among the words there were 64 function words and 47 content words. Many of the function words (e.g., $a$, the, and, but) appeared more than once in the text and these were also presented repeatedly in the single words condition. The quantitative comparison did not show differences in $\mathrm{MC}$ 's reading of lexical categories (34/47 correct in reading text and $36 / 47$ in reading individual words); there were, however, significant differences in his reading of function words $(37 / 64,58 \%$ correct in text, but only 9/64, 14\% when presented as a list); McNemar test, $\chi^{2}(1)=25.48, p<.001$. Whereas the majority of the errors among the content words in text were of omission and a few were of affixation, in the single word condition all errors were of affixation. All function word errors in the single word condition were within-category substitutions and in text reading, most of them were of omission. MC did not make any inflection errors on the nouns. In the text there were seven tensed verbs and one adjectival passive. MC made 3/8 errors on them in connected speech and 7/8 in single word reading.

\section{A summary of the comparison between MC's spontaneous speech, text reading, and single word reading}

The results of the three-way comparison show that function words are considerably better preserved in connected speech and in text reading than in single word reading. Within the context of a sentence, MC does not omit grammatical morphemes and his substitution errors are always closely related to the target. When reading single words, however, he makes unrelated function word substitutions showing that the only information that he can derive from a written function word is that it is a function word. His performance is similar to that of the patients described in Silverberg et al. (1998).

\section{DISCUSSION}

To summarise, the following empirical generalisations can be made about MC's reading, recognition and comprehension of single words.

1. MC displayed a marked difference between his reading of words and of nonwords. Although his reading of morphologically simple words, including low-frequency abstract words (with the exception of function words), was largely intact, he was able to read only $4 \%$ of large sets of nonwords (see Clinical Investigations).

2. MC's reading of free-standing grammatical morphemes was almost as poor as his reading of nonwords (see Clinical Investigations).

3. MC very rarely refused to make a response. His errors were of the following types.

a. In reading morphologically simple content words and nonwords most of his erroneous responses appeared to be visual errors.

b. In reading function words he almost invariably responded with another visually (or otherwise) unrelated function word. His most preferred response was before.

c. He made frequent errors of omission and substitution of affixation in reading derived and inflected words or added a legal derivational affix to morphologically simple words.

4. MC can reliably recognise free-standing grammatical morphemes as words (see task 3); and in a lexical decision task that involved stems and affixed words and nonwords constructed by illegally combining legal stems and affixes, he was consis- 
tently correct in his yes responses but responded with many false positives (see tasks 1 and 2).

5. He could understand the meaning of almost all function words (see tasks 3, 4, 5, and 6) and derivational affixation (see tasks 7 and 8) that we could find a way to test. MC could also understand the meaning of the plural inflection (see task 10).

6. His understanding of the significance of verb inflections is impaired (see tasks 9 and 10).

7. Finally, his severe function word deficit is confined to reading single words. His spontaneous speech, while often ungrammatical, is not devoid of grammatical morphemes. In fact, the proportion of grammatical morphemes in his speech is close to normal and is far better than that of the average nonfluent aphasic (see task 11). At times he makes substitution errors; however, those are very different in nature from his errors in reading single words. His reading of function words in simple texts is also better than his single word reading. His reading of texts resembles the quality of his spontaneous speech.

MC's reading performance fits the pattern described for phonological dyslexia. There is a sharp difference between his ability to read words and nonwords, and his word reading is not affected by factors such as regularity, frequency, length, imageability, and grammatical class, apart from his serious deficit in reading all types of function words. In addition, he makes affixation errors, both omissions and substitutions, on morphologically complex words. We have shown that whereas his phonological skills are relatively well preserved (as he is capable of repeating most nonwords, see Preliminary Investigations), $\mathrm{MC}$ is totally unable to recode graphemes into phonemes and vice versa (see Preliminary Investigations). In our investigations we concentrated on MC's deficits in reading free-standing grammatical morphemes and morphologically complex words, and we will argue that current explanations of the grammatical morpheme deficit in phonological (and deep) dyslexia are inadequate to account for MC's pattern of preserved and impaired reading of single words. MC is a particularly good candidate for such an investigation as his sublexical reading procedure is clearly inoperative and, although his function word reading is very seriously impaired, it presents with a different pattern from his nonword reading.

In the Introduction we suggested that explanations of the grammatical morpheme deficit in phonological dyslexia suggested by Friedman and Patterson et al. implied a link between a deficit in reading function words and abstract words. This is a logical entailment of a theory that interprets the grammatical morpheme deficit as being due to negative features of low semanticity and/or low imageability, as the presence of such features is on a gradient within the class of grammatical morphemes, and the same gradation may be present in other word classes too, especially abstract words. The effects of such gradation in imageability in reading all types of word classes have been studied in two patients by Funnell and Allport (1987). They indeed argued that their patients' reading was affected by semantic considerations, and not by grammatical class.

MC's reading of abstract words, however, is very good (apart from frequent derivational errors), and there was no hint of selectivity in his reading of grammatical morphemes. The $8-16 \%$ of grammatical morphemes he managed to read in every list that he attempted were no different from those that he could not read. The more meaningful and imageable function words such as spatial prepositions and personal pronouns were not read more successfully than grammatical morphemes with less conceptual content. All MC's errors on freestanding grammatical morphemes consisted of substitutions with other grammatical morphemes. In contrast, his most frequent responses to nonwords were visually similar words, and in reading content words too, many of his erroneous responses were visually similar to the target. It seems, then, that $\mathrm{MC}$ is able to make a distinction between function words and nonwords, and approaches them in different ways. His performance, therefore, constitutes evidence against theories that link deficits in function word reading to deficits in nonword reading (Friedman, 1995; Patterson, 1982; Patterson et al., 1996) and against theories that explain grammatical morpheme deficits by their low semanticity and/or imageability (Friedman, 1995; Funnell \& 
Allport, 1987; Patterson, 1982; Patterson et al., 1996). Our data are consistent with the position of Caramazza et al. (1985), who argued that the grammatical morpheme deficit in phonological dyslexic patients is an additional deficit unrelated to the problem of nonword reading, and as such it requires a different explanation.

\section{Why MC cannot read function words}

A great deal of information about function words is available to MC. His well-preserved written lexical decision performance with grammatical morphemes (see task 2) excludes the involvement of the orthographic input lexicon in his deficit. His understanding of the meaning of many written function words (see tasks 3, 4, 5, and 6) indicates that both the semantic representations of function words and the links between representations in the orthographic input lexicon and semantics must be functioning (see also the case of PW described in Morton \& Patterson, 1980). Finally, MC's ability to repeat grammatical morphemes and, especially, to use them in speech excludes the likelihood of an impairment of the phonological representations themselves. Moreover, the within-category errors that he makes when reading them imply that he recognises them as function words.

We argued earlier against explanations of the function word reading deficits in terms of their low imageability or low semanticity (see also Silverberg et al., 1988, for a similar argument). In the following discussion we will interpret MC's selective deficit in reading function words as a syntactic deficit. For this argument to work we have to assume that syntax is not a unitary body of knowledge, and that different modules of syntax may be selectively impaired while others remain intact (see Druks \& Marshall, 1995, and Grodzinsky, 1990, for a similar argument in relation to agrammatism). MC's syntactic deficit is confined to the unavailability of full categorial information attached to function words and may well be a deficit in processing this information. Other aspects of his syntactic knowledge (or of processing this knowledge) may or may not be impaired but they are not relevant to the reading deficit described here. We think that the deficit in relation to function words is syntactic because of the special status of function words in the language, because we have excluded other reasons (such as low imageability and semanticity) for their impairment, and because we know that both the meanings and the phonological forms of many function words are available to MC.

\section{$\mathrm{MC}$ and other relevant patients}

Grammatical morpheme deficits had been discussed in the past, mainly in relation to deep dyslexia and agrammatism. As diagnostic category labels, in our view, do not have central theoretical importance, the grammatical morphemes deficits of these patients are highly relevant to our own discussion. In particular we were interested in reports of patients who, despite an inability to read function words, were able to use these words in continuous speech (Coltheart, 1987; Silverberg et al., 1998a), and in the reported dissociation between the reading of function words in connected text and in isolation (Caramazza \& Hillis, 1989; Nespoulous et al., 1988; Silverberg et al., 1988).

MC's pattern of performance seems to fall into the category of patients described in these studies. Although his spontaneous speech often contains ungrammatical utterances, it is not devoid of grammatical morphemes and inflected words. We think that the ungrammaticality of his speech is due to word-finding difficulties and/or to deficits in sentence planning but unrelated to the unavailability of grammatical morphemes (see example of his spontaneous speech in Appendix $\mathrm{E}$ and its quantitative analysis summarised in Table 7).

One possibility is that $\mathrm{MC}$ cannot read function words in isolation but he may be able to read them within sentential contexts. Indeed, $M C^{\prime}$ 's reading of function words in simple continuous text was considerably better than his reading of them in isolation (see Appendix F). His reading had the quality of a conglomerate of reading and speaking (see a quantitative comparison between his speech and reading in Table 7 , and a transcript of his spontaneous speech and text reading in Appendices $\mathrm{E}$ and F). It seems that MC recognised some of the words and built a sentence around them to the best of his 
ability. This involved the production of some correct and some incorrect grammatical morphemes, a considerable improvement in comparison to his reading of single function words, especially if we note that, when reading, none of the produced function words were entirely inappropriate in the context. He also made a range of errors (additions, omissions, and word order) in reading lexical categories (errors that he, probably, would not have made in single word reading tasks).

Similar improved performance in reading function words within texts by three deep dyslexic patients has been reported by Silverberg et al. They suggested that the improvement was due to support provided by the sentence structure and the presence of content words. In contrast to $\mathrm{MC}$ and the patients in Silverberg et al., Caramazza and Hillis (1989) and Nespoulous et al. (1988) describe patients whose reading of individual function words was intact but very impaired in sentences. These patients were said to have deficits related to sentence planning that affected function words in particular, due to their pivotal role in sentence structure.

Theoretically, two different forms of dissociation are possible. One (unlikely) possibility is that the dissociation is between reading and speaking (of function words). Alternatively, the dissociation may be between the use of isolated function words vs. function words in the context of sentences. In fact it is difficult to distinguish between these two possibilities. MC's reading of simple texts does not suggest that the improved performance is due to his reading of function words when these are presented in texts. Rather, MC and the patients in Silverberg et al.'s study, who are capable of using function words in speech relatively well, probably rely on this knowledge when reading sentences aloud. Thus, their relatively good sentence reading reflects their sentence construction abilities in speech. Moreover, it is likely that all text reading relies intensively on stored knowledge about words and their probable combinations that is available simultaneously for both reading and speaking. Finally, the ultimate comparison between reading and speaking isolated function words (other than in a repetition task) is difficult to carry out. In fact we could not make MC produce isolated function words in any spoken task apart from repetition. We cannot, thus, rule out the possibility that the speaking of isolated function words would also be difficult for MC. Therefore, we concluded that MC's deficit in reading function words may be reformulated as a selective deficit in producing isolated function words, be it in speech or reading.

\section{Processing and linguistic accounts of the grammatical morphemes deficit}

Both theoretical linguistics and psycholinguistics have been paying a great deal of attention to the differences between the nature of lexical and grammatical categories (or open vs. closed class words) and their different processing requirements. The parallels between the linguistic (e.g., Chomsky, 1995) and psycholinguistic processing accounts (e.g., Bock \& Levelt, 1994; Garrett, 1982; Levelt, 1989) are clearly not accidental and reflect the realisation of both disciplines that content words and function words fulfil very different computational roles in sentence construction.

MC's pattern of performance in relation to function words poses two related problems. The first is why he cannot read isolated function words and the second is why his reading of the same items improves when these are embedded within sentences. That the latter is not simply an easier task is demonstrated by patients who show the very opposite pattern (e.g., Caramazza \& Hillis, 1989; Nespoulous et al., 1988). The second question, of why the reading of function words by deep dyslexic patients is improved in sentential contexts, is accounted for by Silverberg et al. using Garrett's sentence processing model.

\section{Garrett's sentence processing model}

Garrett's (e.g., 1982, 1984; Bock \& Levelt, 1994) model of sentence construction distinguishes between the stages of message, functional, and positional levels. For the present concern of making the distinction between open- and closed-class words explicit, the purely linguistic functional and positional levels are relevant. At the functional 
level, the logical framework of a sentence is laid down: abstract forms (lemmas) of major lexical categories (mainly verbs and their arguments but also some prepositions) are selected from the lexicon and are assigned grammatical functions (subject and direct and indirect object). When lemmas are selected (by conceptual activation), grammatical morphemes and bound inflections appropriate to use within the context of a particular lemma (determiners, verbal and nominal inflections, etc.) are also (indirectly) selected by the lemma. By doing so a (sentence) frame is created, punctuated by slots filled with (syntactic) instructions for the required function word and/or inflection to fill in the slot at a later stage. At this stage all lemmas are in an abstract form and word order is not yet specified. At the positional level, all content words are put into their correct sequential order whereby the sentence approximates its surface structure form. This is the stage when major category items become phonological words (or lexemes), though grammatical morphemes still remain in an abstract form. They get their phonological form only at the final stages of sentence construction. In Garrett's system, free and bound grammatical morphemes are treated in the same way, as both are selected indirectly by major lexical categories (lemmas) at the functional level and define the sentence frame. Only some prepositions (spatial and temporal) are conceptually activated together with other lemmas. Other researchers, for example, Lapointe and Dell (1989), on the basis of the evidence that aphasic patients tend to make different type of errors on freestanding grammatical morphemes and inflections (they omit the first and substitute the second), argued that only bound grammatical morphemes define the frame whereas free-standing grammatical morphemes need to be inserted specifically together with the relevant content lemmas.

According to Garrett's model, patients whose ability to construct the sentence frame at the functional level is relatively well preserved will benefit from the presence of structure provided by sentences and will read function words better than when these are in isolation. Moreover, their errors in reading them will be constrained by the grammatical category of the function word, unlike the broad function word substitutions that they make when reading them individually. On the other hand, patients who lost the ability to construct a sentence frame (e.g., the patients reported in Caramazza \& Hillis, 1989; Nespoulous et al., 1988) will be more impaired at reading sentences than single words.

\section{Levelt's model of lexical processing}

Garrett's sentence processing model does not address the question why isolated function words are difficult to read for some dyslexic patients. Levelt's lexical processing model, however, deals directly with single word retrieval. In this model, in accordance with and following Garrett's work, lexical access is in two stages, the lemma and the lexeme levels, relevant for the functional and positional stages respectively. Lemmas are lexical representations activated and selected by the conceptual system. The lemma level is the stage at which concepts become linguistic entities: Words are specified for grammatical class, subcategorisation features, and for a list of permissible inflections and other language relevant features. A feature of this model that is especially relevant for interpreting MC's deficit is that the attainment of both semantic and syntactic specifications is a precondition for accessing the phonological forms of words - the lexemes. In relation to the distinction between content and function words, however, the model (e.g., Levelt, 1992; Levelt, Roelofs, \& Meyer, 1999), unlike Garrett's, does not naturally capture MC's acute problem in reading all function words. In Garrett's theory, the distinction between content and function words is based on whether or not a word participates in word exchanges. Prepositions are an exception as they were found to participate in word exchanges at the functional level. At the (phonological) positional level, however, they behave like other function words-i.e., they do not get involved in sound exchange errors. All other function words are indirectly (i.e., nonconceptually) selected and, therefore, are clearly distinguished from content words. Levelt and colleagues, by contrast, argue that very many function words are, in fact, conceptually activated akin to major category lemmas. The best 
examples are spatial prepositions that have obvious conceptual content, but other function words too have elements of meaning (such as definiteness, gender, tense, aspect, etc.) attached. Only function words with only pure syntactic relevance (e.g., that as a relative pronoun, agreement affixation on verbs, and the case markers to and of) need to be activated indirectly by grammatical encoding.

Levelt's theory, therefore, is able to account for MC's impairment at reading single function words insofar as it claims that access to full lemma representations including syntactic information is an essential precondition for accessing phonological representations (lexemes). Note, however, that in recent debates about the status of the lemma level, Roelofs et al. (1998) qualified this claim by saying that grammatical gender information is selected only if it is required by the task at hand. This, however, does not mean that all syntactic information about single words is superfluous for accessing phonology. Thus, according to the model, a patient who is incapable of constructing the syntactic representation of function words (or of other words), especially information about their grammatical category, will be impaired at accessing their phonological form. The fact that Levelt and colleagues acknowledge that conceptual activation might be relevant not only for content words but also for many function words, in our view, correctly deemphasises the significance of semanticity as the distinguishing feature between content and function words (see Introduction). The distinction that leads to MC's overall deficit in reading function words in isolation is more likely, therefore, to lie in their syntactic properties.

\section{The Independent Network model (Caramazza, 1997)}

An alternative to the lexical processing model of Levelt, the Independent Network (IN) model (Caramazza, 1997), consists of a lexical-semantic network, a network of phonological (and ortho- graphic) lexemes, and a syntactic network. There are no lemma-like abstract amodal lexical representations in this model, and syntactic activation, while important, is not considered a precondition of accessing phonological forms. Some syntactic features (e.g., grammatical category, tense features, and natural gender) are activated by the semantic network but others need the prior activation of the phonological (or orthographic) lexeme. In general, the (weak) activation of syntactic nodes from the semantic network is not sufficient and further activation from the phonological (or orthographic) lexicons is required. Under special circumstances (e.g., TOT states, brain damage), the phonological and orthographic content of the lexeme nodes may become available independently of their grammatical features (Caramazza, 1997, p. 195).

MC's good comprehension of the meaning of single function words and his alleged inability to access full syntactic information about them supports the architecture of the IN model insofar as the model assumes that information about the meaning and the syntax of words are independently represented. But how would the model explain MC's inability to read function words? One possibility is that the deficit is due to the joint effects of weak conceptual activation from the lexical-semantic network with weak phonological representations at the lexeme level. We have argued throughout the paper that low semanticity and/or low imageability were not contributing to $\mathrm{MC}$ 's reading problem. We have also shown that his phonological representations are relatively well preserved and are available to him in speech and in sentence reading ${ }^{1}$. If we are right that the reason for MC's inability to access the phonological form of function words is that he cannot access adequate syntactic information about them, the IN model cannot easily account for his deficit because according to the IN model, access to syntactic information is not an absolute precondition for accessing phonological information about words. Caramazza may have argued that the case of function words is special: In 
the case of function words, activation from both the semantic and phonological networks is too weak and, therefore, syntactic activation is essential (MC's improved reading of function words within sentences might support this).

However, Caramazza did not make such a claim, and a few pages later (1997, p. 199), in order to account for selective grammatical class differences such as MC's (e.g., verbs vs. nouns, function words vs. content words), additional assumptions are incorporated into the model. Two alternatives are suggested: One is that syntactic information about different grammatical classes is represented in different areas in the brain. The second is that lexeme representations (both phonological and orthographic) are organised by grammatical class in different parts of the brain. This is not entirely clear, but we think that in terms of the model, the first alternative implies that the syntactic network is structured according to grammatical class, and the second, that the network of the modality-specific lexemes is so structured. The second alternative, that the output lexicon is structured along grammatical class is, of course, familiar from earlier models of Caramazza and colleagues (e.g., Hillis \& Caramazza, 1995; Rapp \& Caramazza, 1997). This could, in principle, account for MC's selective deficits, but such an organisation of the lexical processing architecture would allocate the syntactic network an extremely restricted role (grammatical class information being structured into the phonological/orthographic networks), making it largely superfluous and, therefore, it is against the spirit of a model that one of its principal components is the syntactic network.

\section{The syntax of single words}

Current linguistic theory (Chomsky, 1995) analyses all function words, with the exception of prepositions, as being different from lexical categories. Garrett's sentence processing theory, which holds that only lexical categories (heads of phrases) are conceptually selected, captures the data similarly to linguistic theory. Both theories suggest that function words are somehow dependent on lexical cate- gories and, therefore, could be difficult to produce in isolation, and both theories have difficulties in explaining MC's deficits in reading prepositions. Prepositions in current syntactic theory have an indeterminate status. On the one hand, prepositions are considered as being functional as they belong to closed-class words, but on the other hand they are lexical, as they are thematic role assigners (see Froud, 2001b). In Garrett's model too they pattern together with lexical categories at the functional level, whereas they are shown to behave similarly to other function words at the positional level. Levelt's theory highlights the fact that many function words have conceptual content and, therefore, meaningfulness is not the best parameter to distinguish between lexical and functional categories.

Both the psycholinguistic and linguistic theories are capable of accounting for MC's reading - up to a point. Nevertheless, we think that there is an advantage in evoking linguistic theory in order to account for the function word deficits of $\mathrm{MC}$ and other such patients. Linguistic theory has the potential of providing detailed analyses of the syntax of different grammatical categories and, therefore, is capable in principle of accounting for fine dissociations within the class of grammatical categories (e.g., dissociations between nominal and verbal inflections (e.g., Luzzatti \& De Bleser, 1996) between determiners and prepositions (Druks, 1991) or between unergative and unaccusative verbs (Froud, 1998, 2001a).

Function words are a mixed set of items including pronouns, prepositions, particles, determiners, wh-words, quantifiers, complementisers, conjunctions, negation words, auxiliaries, and some adverbials. Current linguistic theory provides the impetus to distinguish them from other grammatical categories not by their negative features (short words which do not carry phonological stress, with little meaning) but by their positive syntactic characteristics. Furthermore, the theory licenses the utilisation of syntax not only for the analysis of data consisting of sentences but also for data consisting of single words (see, however, Caramazza, 1997; Friedman \& Grodzinsky, 1997; Miceli et al., 1984, for the contrasting view that data in the form of 
single words cannot yield information about the availability of syntax).

Chomsky proposes that all lexical representations consist of a list of features, which may wholly determine the structural and distributional characteristics of the items with which they are associated. Each lexical entry consists of a listing of these features. For example, a verb (or another major category) is associated with head features, which state whether or not the verb is tensed; specifier features, which state the kind of item that can appear in the verb's specifier position; and complement features, that state the kind of item that can appear as its complement. There must be a match between the specifier features of a verb and the head features of the item that appears in its specifier position. Similarly, the head features of any item in the complement position must match up with the complement features of the verb. Failure to achieve a match will result in an ungrammatical utterance. Lexical representations are even more complex than this. It has been argued (e.g., Grimshaw, 1991) that lexical categories, in addition to their features, also carry information about the functional domain with which they can be associated. This would mean that producing a verb like kiss involves projecting a structure that reflects the fact that verbs are associated with functional heads such as I(nflection) and the production of a noun must involve knowledge of the functional domain associated with nouns, namely, the determiner system. The structure of nouns, however, seems somewhat simpler than that of verbs. The functional heads associated with the checking of features such as number (singular vs. plural) in the determiner phase, DP (e.g., Bhattacharya, 1999; Giusti, 1997), are thought to be located inside the DP itself, unlike functional heads associated with verbs that appear outside the verb phrase (VP). The checking of number on nouns, therefore, is more "local" than the checking of tense on verbs, which requires movement of the verb to a functional head outside the VP. The relative complexity of the functional architecture required by the checking mechanism as it applies to verbs may explain why nouns and noun inflections are often better preserved than verbs and verb inflections in agrammatic patients. This is also true for $\mathrm{MC}$, whose comprehension and production of the plural marker was good while that of verbal inflections was unreliable.

There have been several attempts to understand better the nature of the distinction between lexical and functional categories. In Grimshaw's (1991) view, categories that form part of the same extended projection have identical categorial features. Nouns and functional categories associated with nouns (determiners and prepositions) have the categorial features $[+\mathrm{N},-\mathrm{V}]$, and verbs and functional categories associated with verbs (complementisers and inflectional elements) share the categorial features $[-\mathrm{N},+\mathrm{V}]$. A third feature, $\mathrm{F}$, has the role of distinguishing between lexical and functional categories.

The principal difference between lexical and functional categories is that the production of a functional item in isolation cannot rely on the projection of structural information associated with a lexical head. It is not part of the lexical representation of a functional category that it has a (lexical) complement of a certain type. The extended projection is a property of lexical heads, not of functional heads. Functional categories must, therefore, be represented in a different way from lexical categories: They are part of the extended projection of a lexical head. Thus, according to this linguistic account, the availability of lexical categories supports the production of grammatical morphemes because it is the lexical categories that project their functional domain. The problem involved in producing isolated grammatical morphemes is that functional categories do not project. The speaker/ reader has to create the environment (specifier and complement features) of the isolated functional category. Thus, when a lexical category is being produced, even in isolation, a great deal of information about the possible context of the word becomes available. This is not the case for function words.

This account does not capture all the function words that MC cannot read. First of all it does not capture the case of prepositions that remains controversial in linguistic theory: It is analysed as a major category despite having characteristics shared by functional categories, and despite their vulnerability in the case of agrammatic-type patients (see also Garrett's conception of preposi- 
tions earlier). Furthermore, there are many function words, such as quantifiers, wh-words, or conjunctions and complementisers that do not form part of the extended projection of lexical categories. Nevertheless, these items pattern with other functional categories in $\mathrm{MC}$ 's reading (and that of other patients) and they are clearly identified as functional within current linguistic theory. One consequence of this distinction is that whereas the production of function words that are part of the extended projection of major categories is expected to improve in text reading, no such improvement is expected in relation to other function words. There is some indication in MC's text reading that this might be the case. For example, he totally ignored words such as when, which, and but in his reading. The testing of this hypothesis, however, would need much more work.

\section{Morphologically complex words}

MC's reading of morphologically complex wordsboth derived and inflected-is seriously impaired, though it is better than his reading of free-standing grammatical morphemes. Although the information that MC is capable of extracting from a function word is minimal, in the case of bound morphemes, the stem constrains the pool of permissible affixes and therefore, by default, he responds correctly on average approximately $50 \%$ of the time.

Traditional aphasia literature has been preoccupied in the past with the distinction between omission and substitution of grammatical morphemes. Broca's aphasics were said to omit grammatical morphemes (agrammatism), whereas Wernicke's aphasics were said to use them wrongly (paragrammatism). Since Grodzinsky (1990) has successfully argued against this position, the generalisation is no longer held. Indeed, MC made all types of errors, omissions, substitutions, and also additions of derivational affixes to morphologically simple words (always producing well-formed words however).

Linguistics distinguishes between derivational and inflectional affixation as two distinct wordformation processes-derivational morphology affecting the lexicon and creating word class alterations, and inflectional morphology affecting syntax. Following this distinction, it has been argued (e.g., De Bleser \& Bayer, 1988; Grodzinsky, 1990; Kolk, 1978; Miceli \& Caramazza, 1988) that in agrammatism - an allegedly syntactic deficitderivational morphology is preserved while inflectional morphology is impaired. Our results, based on reading long lists of derived and inflected words, however, do not provide support for this generalisation. MC's reading of derived words is no better than his reading of inflected words (see Clinical Investigations, Reading Derived and Inflected Words, and other reading lists with verbs and abstract words). In fact, his reading of plural nouns and of gerundive verbs-both inflectional-was better preserved than his reading of derived words.

In reports of deep and phonological dyslexia patients, derivational and inflectional errors are described and discussed together. The two types of errors tend to co-occur in individual patients (but see Job \& Sartori, 1984) and, to our knowledge, no arguments have yet been offered to explain the rationale for the co-occurrence of this two types of errors in reading disorders despite the linguistic distinctions between derivation and inflection. The problem is very apparent if Garrett's model is considered. In Garrett's sentence production model, lexical categories (including derived words such as commitment) are conceptually activated (Garrett's model does not deal with possible morphological processing within the lexicon that constructs commitment from commit). Grammatical morphemes and inflections associated with the lemma, on the other hand, are selected by the lemma and constitute the sentence frame into which the conceptually selected items will eventually slot. Thus the time course involved in the processing of derivational and inflectional morphology in sentence development is very different. Therefore it is surprising that no more patients in whom the two processes dissociate have been described. It seems that in the case of MC and other such patients the impairment is not sensitive enough to distinguish between two very different but nevertheless comparable processes involving productive function markers (such as $-s$, the marker of plurality, $-e d$, the marker of past 
tense, $-e r$, the marker of an agency, or $-l y$, the marker of adverbials and of free-standing grammatical morphemes). MC's reading pattern suggests that despite the difference in terms of meaning, syntax, and the time of operation between derivational and inflectional processes, there is a theoretical link between all free and bound grammatical morphemes that results in their being lesioned together (see Froud, 2001a, who argues that the theoretical link is to be found in the morphology component of the grammar). It is possible, however, that in future we will find patients whose deficit will distinguish between derivational and inflectional affixes and different types of freestanding grammatical morphemes.

MC's deficits in reading inflected and derived words are accompanied by considerable knowledge of the morphological makeup of words. In task 2, a lexical decision task involving stems and affixed words and nonwords constructed by illegally combining legal stems and affixes, MC always correctly accepted legal words but he often accepted the illegal combinations too. As his lexical decision has always been reliable and he is known not to overuse yes responses, we were inclined to interpret this high rate of false positives as being due to correct recognition of stem and affix, but an inability to judge the legality of their combination. He also distinguished between affixed and pseudoaffixed words (see Clinical Investigations) by making affixation errors only on the former. Both pieces of evidence are consistent with the view that assumes representations in which morphologically complex words are decomposed into stem and affix at some level of the lexical derivation (e.g., Badecker \& Caramazza, 1991; Caramazza, Laudanna, \& Romani, 1988; Laudanna, Cermele, \& Caramazza, 1997).

MC's performance on tasks that tapped his understanding of the meanings of derivational and inflectional affixation was most interesting. His sorting of derived words into agents and non agents and into males and females was confident and errorless (see tasks 7 and 8). His performance with inflectional morphology, however, was more variable. He was able to distinguish reliably between singular and plural nouns (see task 10), but his per- formance declined when sorting different forms of tensed verbs (see task 11) or when asked to choose one verb form suitable for a sentence frame from a choice of four (see task 9).

Thus, there is a difference in his understanding of the meaning of different types of affixation. MC's deficit of derivational affixation and of the plural inflection is similar to that of free-standing grammatical morphemes. He makes many omission and substitution errors in reading them but he can understand their meaning. Verb inflections, however, are more seriously impaired in that his understanding of their significance is also unreliable. It is difficult to be precise about which aspects of verbal inflections are particularly difficult for $\mathrm{MC}$ because of the impoverished verbal inflection system in English, though MC's performance on the verb sorting task tentatively suggested that tense features might be better preserved (in input tasks such as sorting different verb forms, or sentence completion) than agreement features. We also have some evidence, not reported here, that $\mathrm{MC}$ is impaired in auditory grammaticality judgement tasks involving agreement. It has been suggested that whereas tense is conceptually activated at the lemma level, agreement, being dependent on other elements in the sentence, is set at grammatical encoding (Levelt et al., 1999). This could account for MC's different responses to tense and agreement markers (but see Friedman \& Grodzinsky, 1997) who report the case of a Hebrew speaking agrammatic patient with the reverse dissociation). However, MC's problems with verb inflections over and above his deficits in reading them are not the focus of the present paper and a proper discussion of these issues would require further research.

\section{Summary}

We have interpreted MC's difficulty in the reading of single function words, derived words, and inflected words as being due to the unavailability of syntactic information attached to these items. While this deficit has a serious detrimental effect on the production of these items, their recognition and comprehension remains relatively intact. MC's deficit in reading single function words may be 
accounted for by the lemma model, according to which access to syntactic information about words - their grammatical category, subcategory, the inflections that are permissible with the word, and other word related information-must be available prior to accessing the phonological form of words.

MC's improved production of function words in spontaneous speech and in the reading of texts shows that he is still capable of accessing syntactic information for lexical categories that involve the construction of their extended projection, which includes functional categories. Garrett's sentence production model, in which function words and inflections are selected by lexical categories that, when selected, define the sentence frame, is similarly able to account for improved reading (and speaking) of function words within the context of a sentence.

Manuscript received 30 August 1999 Revised manuscript received 24 January 2001 Revised manuscript accepted 25 July 2001

\section{REFERENCES}

Allport, D.A., \& Funnell, E. (1981). Components of the mental lexicon. Philosophical Transactions of The Royal Society of London, 295B (1077), 397-410.

Andreewsky, E., \& Seron, X. (1975). Implicit processing of grammatical rules in a classical case of agrammatism. Cortex, 9, 379-390.

Badecker, W., \& Caramazza, A. (1991). Morphological composition in the lexical output system. Cognitive Neuropsychology, 8, 335-367.

Berndt, R.S., Haendiges, A.N., Mitchum, C.C., \& Wayland, S.C. (1996). An investigation of nonlexical reading impairments. Cognitive Neuropsychology, 13, 763-801.

Berndt, R.S., Wayland, S.C., Rochon, E., Saffran, E.M., \& Schwartz, M.F. (2000). Quantitative production analysis. Hove, UK: Psychology Press.

Bhattacharya, T. (1999). The structure of the Bangla DP. Unpublished $\mathrm{PhD}$ dissertation, UCL, London, UK.

Bock, K., \& Levelt, W. (1994). Language production: Grammatical encoding. In M.A. Gernsbacher (Ed.),
Handbook of psycholinguistics. San Diego, CA: Academic Press.

Campbell, R., \& Butterworth, B. (1985). Phonological dyslexia and dysgraphia in a highly literate subject: A developmental case with associated deficits of phonemic processing and awareness. The Quarterly Journal of Experimental Psychology, 37A, 435-475.

Caramazza, A. (1997). How many levels of processing are there in lexical access? Cognitive Neuropsychology, 14, 177-208.

Caramazza, A., \& Hillis, A. (1989). The disruption of sentence production: Some dissociations. Brain and Language, 36, 625-650.

Caramazza, A., Laudanna, A., \& Romani, C. (1988). Lexical access and inflectional morphology. Cognition, 28, 297-334.

Caramazza, A., Miceli, G., Silveri, M.C., \& Laudanna, A. (1985). Reading mechanisms and the organization of the lexicon: Evidence from acquired dyslexia. Cognitive Neuropsychology, 2, 81-114.

Chomsky, N. (1995). The minimalist program. Cambridge, MA: MIT Press.

Coltheart, M. (1987). Deep dyslexia: A review of the syndrome. In M. Coltheart, K. Patterson, \& J.C. Marshall (Eds.), Deep dyslexia. (2nd ed). London: Routledge \& Kegan Paul.

Coltheart, M., Besner, D., Jonasson, J.T., \& Davelaar, E. (1979). Phonological encoding in the lexical decision task. Quarterly Journal of Experimental Psychology, 31, 489-507.

De Bleser, R., \& Bayer, J. (1988). On the role of inflectional morphology in agrammatism. In $\mathrm{M}$. Hammond \& M. Noonan (Eds.), Theoretical morphology: Approaches in modern linguistics. New York: Academic Press.

Druks, J. (1991). Agrammatic aphasia with special reference to Hebrew. Unpublished doctoral thesis, The Open University, Milton Keynes, UK.

Druks, J., \& Marshall, J.C. (1995). When passives are easier than actives. Two case studies of comprehension in Broca's aphasia. Cognition, 55, 311-331.

Druks, J., \& Masterson, J. (2000). An object and action naming test. Hove, UK: Psychology Press.

Dunn, L.M., Dunn, L.M., Whetton, C., \& Pintilie, D. (1982). British Picture Vocabulary Scale. Windsor, UK: NFER-Nelson.

Francis, W.N., \& Kucera, H. (1982). Frequency analysis of English usage: Lexicon and grammar. Boston: Houghton Mifflin.

Friederici, A.D. (1981). Production and comprehension of prepositions in aphasia. Neuropsychologia, 19, 191199. 
Friederici, A.D. (1982). Syntactic and semantic processes in aphasic deficits: The availability of prepositions. Brain and Language, 15, 249-258.

Friederici, A.D., \& Schonle, P.W. (1980). Computational dissociation of two vocabulary types: Evidence from aphasia. Neuropsychologia, 15, 249-258.

Friedman, R.B. (1995). Two types of phonological alexia. Cortex, 31, 397-403.

Friedman, N., \& Grodzinsky, Y. (1997). Tense and agreement in agrammatic production: Pruning the syntactic tree. Brain and Language, 56, 397-425.

Froud, K. (1998). Aphasic evidence for the syntactic determination of unaccusativity. UCL Working Papers in Linguistics, 10, 369-387.

Froud, K. (2001a). Agrammatism and the minimalist program: Evidence for the morphology interface from a case of acquired language pathology. Unpublished $\mathrm{PhD}$ dissertation, UCL, UK.

Froud, K. (2001b). Prepositions and the lexical functional divide: Aphasic evidence. Lingua, 111, 1-28.

Funnell, E. (1983). Phonological processes in reading: New evidence from acquired dyslexia. British Journal of Psychology, 74, 159-180.

Funnell, E. (1987). Morphological errors in acquired dyslexia: A case of mistaken identity. Quarterly Journal of Experimental Psychology, 39A, 497-538.

Funnell, E., \& Allport, A. (1987). Nonlinguistic cognition and word meanings: Neuropsychological exploration of common mechanisms. In A. Allport, D.D. Mackay, W. Prinz, \& E. Scheerer (Eds.), Language perception and production: Relationships between listening, speaking, reading and writing. London: Academic Press.

Gardner, H., \& Zurif, E.B. (1975). Bee but not be: Oral reading of single words in aphasia and alexia. Neuropsychologia, 13, 181-190.

Garrett, M.F. (1982). Production of speech: Observations from normal and pathological language use. In A.W. Ellis (Ed.), Normality and pathology in cognitive functions. London: Academic Press.

Garrett, M.F. (1984). The organization of processing structure for language production: Application to aphasic speech. In D. Caplan, A.R. Lecours, \& A. Smith (Eds.), Biological perspectives on language. Cambridge, MA: MIT Press.

Giusti, G. (1997). The categorial status of determiners. In L. Haegeman (Ed.), The new comparative syntax. London: Longman.

Glushko, R.J. (1979). The organisation and activation of orthographic knowledge in reading aloud. Journal of Experimental Psychology: Human Perception and Performance, 5, 674-691.
Goodenough, C., Zurif, E.B., \& Weintraub, S. (1977). Aphasics' attention to grammatical morphemes. Language and Speech, 20, 11-19.

Goodglass, H. (1976). Agrammatism. In H. Whitaker \& H.A. Whitaker (Eds.), Studies in neurolinguistics, Vol. 1. New York: Academic Press.

Goodglass, H., \& Kaplan, E. (1972). The assessment of aphasia and related disorders. Philadelphia, PA: Lea \& Febiger.

Grimshaw, J. (1991). Extended projection. Unpublished manuscript, Linguistics and Cognitive Science Program, Brandeis University.

Grodzinsky, Y. (1988). Syntactic representation in agrammatism: The case of prepositions. Language and Speech, 31, 115-134.

Grodzinsky, Y. (1990). Theoretical perspectives on language deficits. Cambridge, MA: MIT Press.

Hillis, A.E., \& Caramazza, A. (1995). Representation of grammatical categories of words in the brain. Journal of Cognitive Neuroscience, 7, 396-407.

Howard, D. (1991). Letter-by-letter reading: Evidence for parallel processing. In D. Besner, \& G.W. Humphreys (Eds.), Basic processes in reading: Visual word recognition. Hillsdale, NJ: Lawrence Erlbaum Associates Inc.

Howard, D., \& Patterson, K. (1992). The Pyramids and Palm Trees Test. Bury St Edmunds, UK: Thames Valley Test Company.

Isserlin, M. (1922). Über Agrammatismus. Zeitschrift für die gesamte Neurologie und Psychiatrie, 75, 332-416. (English translation, 1985, in Cognitive Neuropsychology, 2, 303-345.)

Job, R., \& Sartori, G. (1984). Morphological decomposition: Evidence from crossed phonological dyslexia. The Quarterly Journal of Experimental Psychology, 36A, 435-458.

Jones, G.V. (1985). Deep dyslexia, imageability, and ease of predication. Brain and Language, 24, 1-19.

Kaplan, E., Goodglass, H., \& Weintraub, S. (1983). Boston Naming Test. Philadelphia, PA: Lea \& Febiger.

Kay, J., Lesser, R., \& Coltheart, M. (1992). PALPA: Psycholinguistic Assessments of Language Processing in Aphasia. Hove, UK: Lawrence Erlbaum Associates Ltd.

Kean, L.M. (1977). The linguistic interpretation of aphasic syndromes. Cognition, 5, 9-46.

Kolk, H.H.J. (1978). The linguistic interpretation of Broca's aphasia. A reply to M.L. Kean. Cognition, 6, 353-361.

Lapointe, S.G. (1985). A theory of verb form use in the speech of agrammatic aphasics. Brain and Language, 24, 100-155. 
Lapointe, S.G., \& Dell, G. (1989). A synthesis of some recent work in language production. In G. Clarlson and M. Tannenhaus (Eds.), Linguistic structure and language processing. Dordrecht, The Netherlands: Kluwer.

Laudanna, A., Cermele, A., \& Caramazza, A. (1997). Morpho-lexical representations in naming. Language and Cognitive Processes, 12, 49-66.

Lesch, M.F., \& Martin, R.C. (1998). The representation of sublexical orthographic-phonologic correspondences: Evidence from phonological dyslexia. The Quarterly Journal of Experimental Psychology, 51A, 905-938.

Levelt, W.J.M. (1989). Speaking: From intention to articulation. Cambridge, MA: MIT Press.

Levelt, W.J.M. (1992). Accessing words in speech production: Stages, processes and representations. Cognition, 42, 1-22.

Levelt, W.J.M., Roelofs, A., \& Meyer, A.S. (1999). A theory of lexical access in speech production. Behavioral and Brain Sciences, 22(1), 1-38.

Luzzatti, C., \& De Bleser, R. (1996). Morphological processing in Italian agrammatic speakers: Eight experiments in lexical morphology. Brain and Language, 54, 26-74.

Masterson, J. (1985). On how we read nonwords: Data from different populations. In K.E. Patterson, J.C. Marshall, \& M. Coltheart, (Eds.), Surface dyslexia. Hove, UK: Lawrence Erlbaum Associates Ltd.

Miceli, G., \& Caramazza, A. (1988). Dissociation of inflectional and derivational morphology. Brain and Language, 35, 24-65.

Miceli, G., Silveri, M.C., Romani, C., \& Caramazza, A. (1989). Variation in the pattern of omissions and substitutions of grammatical morphemes in the spontaneous speech of so-called agrammatic patients. Brain and Language, 36, 447-492.

Miceli, G., Silveri, M.C., Villa, G., \& Caramazza, A. (1984). On the basis for the agrammatic's difficulty in producing main verbs. Cortex, 20, 207-220.

Morton, J., \& Patterson, K. (1980). "Little words-No!" In M. Coltheart, K. Patterson, \&J.C. Marshall (Eds.), Deep dyslexia. London: Routledge \& Kegan Paul.

Nespoulous, J.L., Dordain, M., Perron, C., Ska, B., Bub, D., Caplan, D., Mehler, J., \& Lecours, A.R. (1988). Agrammatism in sentence production without comprehension deficits: Reduced availability of syntactic structures and/or of grammatical morphemes: A case study. Brain and Language, 33, 273-295.

Ouhalla, J. (1993). Functional categories, agrammatism and language acquisition. Linguistische Berichte, 143, 3-36.
Parkin, A.J. (1984). Redefining the regularity effect. Memory and Cognition, 12, 287-292.

Patterson, K.E. (1982). The relation between reading and phonological coding: Further neuropsychological observations. In A. Ellis (Ed.), Normality and pathology in cognitive functioning. London: Academic Press.

Patterson, K.E., \& Marcel, A. (1992). Phonological ALEXIA or PHONOLOGICAL alexia? In J. Alegria, D. Holender, J. Junca de Morais, \& M. Radeau (Eds.), Analytic approaches to human cognition. Amsterdam: Elsevier Science Publishers.

Patterson K.E., Suzuki, T., \& Wydell, T.N. (1996). Interpreting a case of Japanese phonological alexia: The key is in phonology. Cognitive Neuropsychology, 13, 803-822.

Radford, A. (1997). Syntactic theory and the structure of English: A minimalist approach. Cambridge: Cambridge University Press.

Rapp, B., \& Caramazza, A. (1997). The modalityspecific organisation for grammatical categories: Evidence from impaired spoken and written sentence production. Brain and Language, 56, 248-286.

Roelofs, A., Meyer, A.S., \& Levelt, W.J.M. (1998). A case for the lemma/lexeme distinction in models of speaking: comment on Caramazza and Miozzo (1997). Cognition, 69, 219-230.

Saffran, E.M., Schwartz, M.F., \& Marin, O.S.M. (1979). Neuropsychological evidence for mechanisms of reading: I. Deep dyslexia. Paper presented to the Seventh International Neuropsychology Society Meeting, New York.

Saffran, E.M., Schwartz, M.F., \& Marin, O.S.M. (1980). The word order problem in agrammatism II: Production. Brain and Language, 10, 249-262.

Sasanuma, S., Ito, H., Patterson, K.E., \& Ito, T. (1996). Phonological alexia in Japanese: A case study. Cognitive Neuropsychology, 13, 823-848.

Shallice, T. (1988). From neuropsychology to mental structure. Cambridge: Cambridge University Press.

Shallice, T., \& Plaut, D. (1992). From connectionism to neuropsychological syndromes. In J. Alegria, D. Holender, J. Junca de Morais, \& M. Radeau (Eds.), Analytic approaches to human cognition. Amsterdam: Elsevier Science Publishers.

Shallice, T., \& Saffran, E.M. (1986). Lexical processing in the absence of explicit word identification: Evidence from a letter-by-letter reader. Cognitive Neuropsychology, 3, 429-458.

Shallice, T., \& Warrington, E.K. (1980). Single and multiple component central dyslexic syndromes. In M. Coltheart, K. Patterson, \& J.C. Marshall (Eds.), Deep dyslexia. London: Routledge \& Kegan Paul. 


\section{DRUKS AND FROUD}

Silverberg, N., Vigliocco, G., Insalaco, D., \& Garrett, M. (1998). When reading a sentence is easier than reading a "little" word: The role of production processes in deep dyslexics' reading aloud. Aphasiology, 12, 335-357.
Zurif, E.B., Green, E., Caramazza, A., \& Goodenough, C. (1976). Grammatical intuitions of aphasic patients: Sensitivity to functors. Cortex, 12, 183-186.

\section{APPENDIX A}

\section{MC's diagnostic profile on the Boston Diagnostic Aphasia Examination}

\section{MELODIC LINE \\ intonational contour \\ PHRASE LENGTH \\ longest occasional \\ uninterrupted \\ word runs}

ARTICULATORY AGILITY

facility at phonemic and

syllable level

GRAMMATICAL FORM

variety of grammatical constructions (even if

incomplete)

PARAPHASIA IN

RUNNING SPEECH

\section{REPETITION}

score in High-Probability subtest

WORD FINDING informational content in relation to fluency

\section{AUDITORY}

COMPREHENSION

mean of percentiles

on 4 Auditory Comprehen-

sion subtests
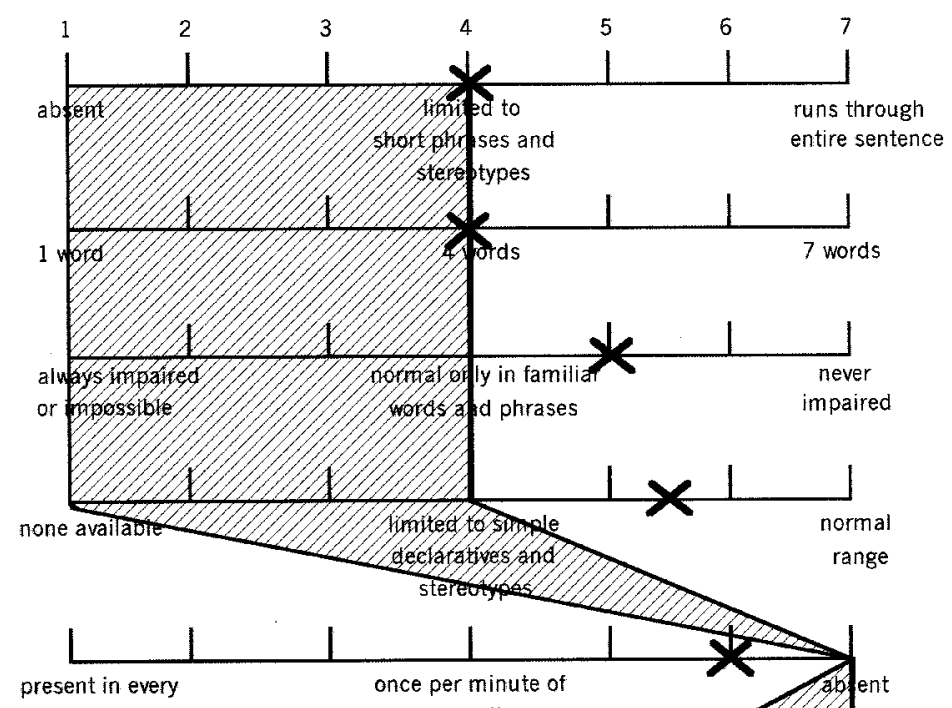

utterance

conversation
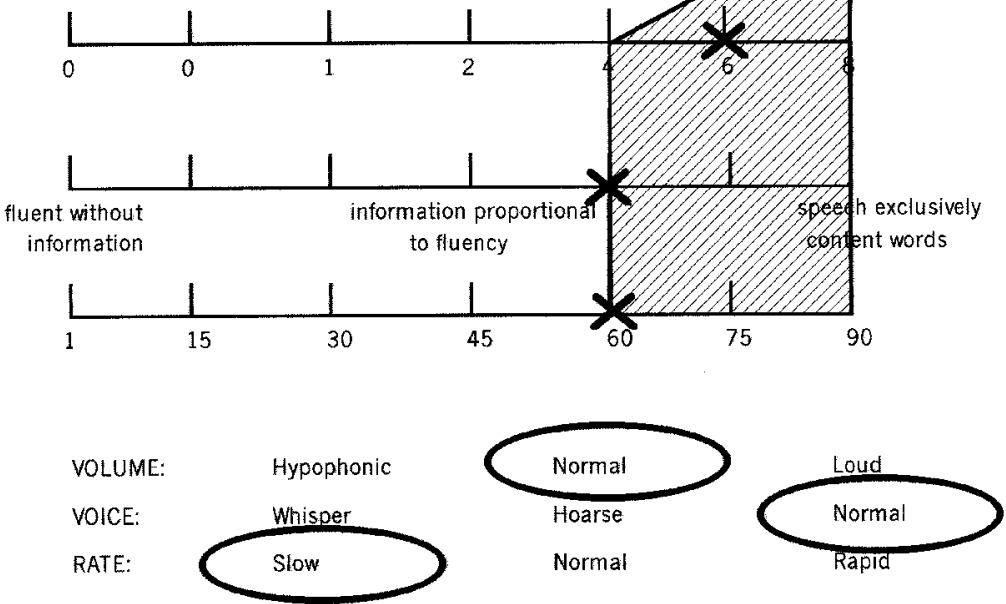

(Shaded area indicates predicted range of ratings for Broca's aphasia) 
The function words presented to $\mathrm{MC}$ for reading and his responses in two separate lists subdivided according to their grammatical categories

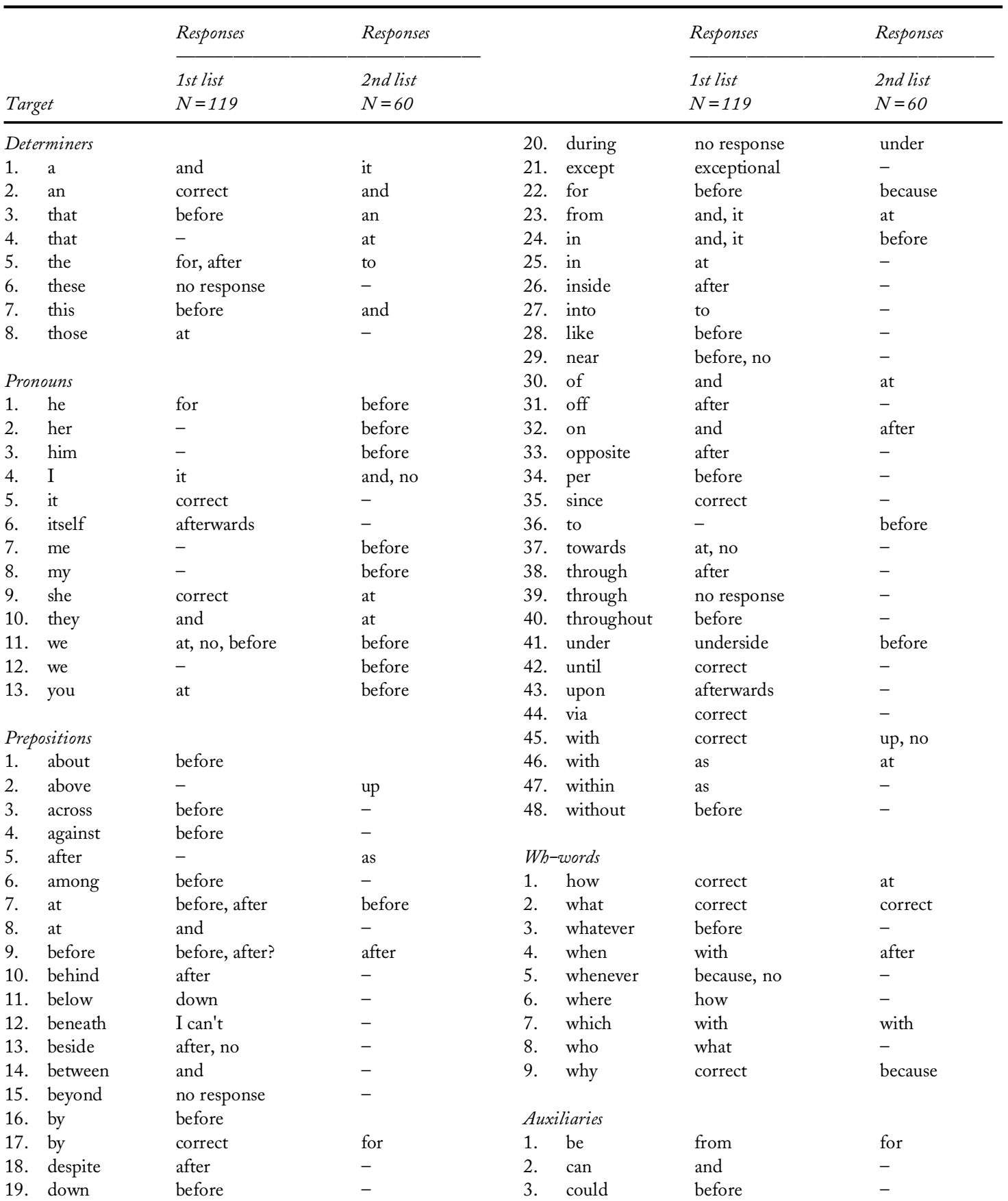




\begin{tabular}{|c|c|c|c|c|c|}
\hline \multirow[b]{2}{*}{ Target } & Responses & Responses & & Responses & Responses \\
\hline & $\begin{array}{l}\text { 1st list } \\
N=119\end{array}$ & $\begin{array}{l}2 n d \text { list } \\
N=60\end{array}$ & & $\begin{array}{l}1 s t \text { list } \\
N=119\end{array}$ & $\begin{array}{l}2 n d \text { list } \\
N=60\end{array}$ \\
\hline 4. do & before & for, to & 9. yet & before & at \\
\hline 5. have & for & - & 10. then & but & at \\
\hline 6. may & before & - & 11. then & before & - \\
\hline 7. might & before & - & 12. there & before & - \\
\hline 8. must & before & - & 13. up & - & correct \\
\hline 9. shall & at & - & & & \\
\hline 10. should & before & - & Complementisers & & \\
\hline 11. will & at & - & 1. if & and & an \\
\hline 12. would & was & - & 2. whether & no response & - \\
\hline \multicolumn{3}{|l|}{ Conjunctions } & \multicolumn{3}{|l|}{ Ouantifiers } \\
\hline 1. also & before & - & 1. all & for, no, at & before \\
\hline 2. although & after & after & 2. any & after & - \\
\hline 3. and & correct & because & 3. anyone & after & - \\
\hline as & and & - & 4. anything & before, no & \\
\hline 5. because & before & before & 5. every & after & - \\
\hline 6. but & before & correct & 6. everyone & before & - \\
\hline 7. however & before & - & 7. few & - & for \\
\hline 8. nor & for, no & - & 8. many & - & for \\
\hline 9. or & and & as & 9. most & - & after \\
\hline 10. so & what, no & at & 10. some & correct & after \\
\hline \multirow[t]{2}{*}{ 11. unless } & at & - & & & \\
\hline & & & \multicolumn{3}{|l|}{ Negation words } \\
\hline \multicolumn{3}{|l|}{ Adverbs } & 1. not & it & correct \\
\hline 1. ago & as & - & 2. no & correct & - \\
\hline 2. almost & after & - & & & \\
\hline 3. already & before & - & Adjectives & & \\
\hline 4. even & it & - & 1. just & before & before \\
\hline 5. out & and & correct & 2. less & at & - \\
\hline 6. over & after & before & 3. next & - & because \\
\hline 7. too & before & - & 4. now & - & at \\
\hline 8. usually & before & - & 5. only & at & - \\
\hline
\end{tabular}




\section{APPENDIX C}

A list of concrete and abstract words matched for frequency selected from the MRC Psycholinguistic Database

\begin{tabular}{|c|c|c|c|c|}
\hline $\begin{array}{l}\text { Abstract } \\
\text { words }\end{array}$ & $\begin{array}{c}\text { Concreteness } \\
\text { ratings }\end{array}$ & Frequency & $\begin{array}{c}\text { Concrete } \\
\text { words }\end{array}$ & $\begin{array}{c}\text { Concreteness } \\
\text { ratings }\end{array}$ \\
\hline abrupt & 266 & 18 & bell & 620 \\
\hline admire & 296 & 10 & balloon & 623 \\
\hline alias & 232 & 1 & apricot & 638 \\
\hline beg & 300 & 11 & cement & 646 \\
\hline belief & 270 & 64 & rifle & 606 \\
\hline blame & 293 & 34 & pencil & 617 \\
\hline capacity & 293 & 83 & ship & 615 \\
\hline concept & 264 & 85 & rose & 608 \\
\hline concert & 252 & 39 & stick & 604 \\
\hline deceit & 257 & 2 & birch & 620 \\
\hline delight & 282 & 29 & barn & 614 \\
\hline depict & 262 & 3 & chalk & 634 \\
\hline facility & 279 & 11 & drum & 602 \\
\hline fantasy & 295 & 14 & pie & 613 \\
\hline fate & 255 & 33 & jacket & 635 \\
\hline gallant & 240 & 5 & eagle & 616 \\
\hline generous & 260 & 15 & penny & 606 \\
\hline gist & 273 & 1 & blouse & 640 \\
\hline honour & 258 & 2 & broom & 613 \\
\hline humble & 231 & 18 & lamp & 615 \\
\hline ideal & 253 & 61 & beach & 612 \\
\hline jeopardy & 266 & 4 & banana & 633 \\
\hline logic & 250 & 4 & lion & 627 \\
\hline magic & 257 & 17 & chicken & 614 \\
\hline marvel & 293 & 6 & goat & 636 \\
\hline meek & 299 & 10 & button & 613 \\
\hline nice & 279 & 75 & rock & 600 \\
\hline oblivion & 242 & 2 & cider & 626 \\
\hline opinion & 285 & 96 & film & 604 \\
\hline passion & 300 & 28 & sand & 616 \\
\hline pathetic & 256 & 8 & diamond & 610 \\
\hline predict & 288 & 8 & ankle & 608 \\
\hline pride & 270 & 42 & bag & 603 \\
\hline regret & 260 & 9 & apple & 620 \\
\hline risk & 290 & 54 & phone & 624 \\
\hline sane & 290 & 8 & newt & 606 \\
\hline scarce & 297 & 6 & spoon & 614 \\
\hline scorn & 290 & 4 & ornament & 615 \\
\hline severe & 286 & 39 & stick & 604 \\
\hline shame & 287 & 21 & skirt & 614 \\
\hline slow & 293 & 60 & garden & 602 \\
\hline soul & 289 & 47 & skin & 614 \\
\hline stifle & 292 & 2 & flea & 625 \\
\hline tempt & 283 & 2 & hedge & 615 \\
\hline unique & 300 & 58 & stone & 614 \\
\hline upset & 282 & 14 & hawk & 623 \\
\hline vary & 258 & 34 & sugar & 620 \\
\hline weird & 253 & 10 & thermometer & 612 \\
\hline wish & 270 & 110 & ball & 615 \\
\hline yore & 267 & 2 & owl & 614 \\
\hline
\end{tabular}




\section{APPENDIX D}

\section{A list of function and content words matched for imageability selected from the MRC Psycholinguistic Database}

\begin{tabular}{llllllll}
\hline $\begin{array}{l}\text { Function } \\
\text { words }\end{array}$ & $\begin{array}{c}\text { Imageability } \\
\text { ratings }\end{array}$ & $\begin{array}{c}\text { Function } \\
\text { words }\end{array}$ & $\begin{array}{c}\text { Imageability } \\
\text { ratings }\end{array}$ & $\begin{array}{c}\text { Content } \\
\text { words }\end{array}$ & $\begin{array}{c}\text { Imageability } \\
\text { ratings }\end{array}$ & $\begin{array}{c}\text { Content } \\
\text { words }\end{array}$ & $\begin{array}{c}\text { Imageability } \\
\text { ratings }\end{array}$ \\
\hline an & 195 & why & 251 & gybe & 190 & criterion & 250 \\
but & 206 & not & 253 & amity & 205 & audit & 253 \\
the & 209 & before & 255 & circumstance & 210 & morass & 256 \\
than & 213 & only & 255 & stipend & 213 & latter & 56 \\
for & 216 & where & 255 & panoply & 213 & concept & 258 \\
a & 217 & which & 257 & noisy & 215 & enigma & 259 \\
of & 217 & into & 259 & yore & 218 & actual & 259 \\
or & 224 & who & 261 & aster & 224 & dirge & 262 \\
at & 225 & also & 264 & abstruse & 225 & rote & 264 \\
and & 226 & since & 264 & plaice & 226 & consider & 264 \\
if & 228 & every & 267 & byre & 231 & analogy & 267 \\
by & 229 & these & 267 & acumen & 229 & apparent & 266 \\
how & 230 & thus & 267 & synod & 229 & essential & 268 \\
when & 231 & on & 268 & aspect & 233 & factor & 268 \\
from & 239 & ever & 273 & usual & 235 & worth & 269 \\
nor & 243 & this & 279 & verity & 240 & foible & 275 \\
therefore & 243 & there & 283 & slough & 245 & former & 279 \\
very & 243 & against & 285 & allegory & 244 & reason & 283 \\
because & 244 & with & 287 & accord & 248 & fallacy & 285 \\
however & 247 & anyone & 288 & extent & 248 & exact & 287 \\
those & 247 & both & 298 & consist & 249 & aware & 288 \\
what & 249 & & & instance & 250 & & 298 \\
\hline
\end{tabular}




\section{APPENDIX E}

\section{A sample of MC's spontaneous speech: Sleeping Beauty-the ballet}

Once upon a time.. There was a prince and princess. And they are going a baby. Erm... the.. baby is arrived and it is the christening to... erm...erm...the all the gentry were present... [5 sec] and in the gallery was lots of fairies which, which dancing, and erm each one took to point to the baby and erm...and...like...like to give a present. Erm, but I can't do the fairy individually. Okay, erm... It is sixteen. [What happened with the fairies?] Oh no, the other thing is the wicked fairy, the curse, which is a pin, or a - what's the thing called...a bodkin? Erm.. which will die. But it is not very much and so they just to go together and so they went to the party and that's that. And grown up it is sixteen, and it's a long time ago but there we are. And sixteen, and the little child is a lovely girl. Erm, the...the erm.. girl, are dancing, and they go to/suitiers/ (= suitors?), which is very nice idea. The king and queen are very delighted. Erm, so they're all dancing, very well, and they are, which, er, which we want to do, and er... dancing, and maybe one or the other is proposing but I don't like it very much and in er the wicked fairy, ah, and she, a spell. And the dancers all positioned just so, and the girl, Sleeping Beauty, is gone to the bed and asleep. It is, I can't remember how many years, twenty or something like that, twenty I think, I don't know [Usually a hundred, I think] Hundred, that's right, yes a hundred, that's right. And they're all sleeping, and, oh the fairy, the wise one has a spell, like trees and bushes and things like that, impenetrable, and it is very tough to go in it, but it is a spell and that is that. And it is an hundred years past again, and it was a prince, erm...Very nice and erm, went into the forest, and erm the party departed but the princess lives on. The wicked fairy, the last one of the fairies, erm, is er, going, and it is a boat to all the lands far off. The princess stops when it is down to the ... forest of the ... of the... princess, no the prince. erm, hacking and things like that. [What did the prince do?] Well, erm, hacked and hacked and hacked, and there was the castle, which she, he, broke in and up to the bedroom. There is a girl and she is such a lovely girl that the prince kissed her. And, er, the whole thing started again, the courtiers the dancers and thing like that. And she is very beautiful and she likes to dance, and the prince, prince and princesses are delighted, and all is very happy. 


\section{APPENDIX F}

\section{The reading text presented to $\mathrm{MC}$}

Once upon a time there was a prince and princess, and they were going to have a baby. When the baby arrived there was a christening at which all the gentry were present. In the gallery were lots of fairies dancing, and each one took a turn to point to the baby and give a present. But the wicked fairy cursed a spindle and said that the baby would die when she touched it.

A long time later, the baby had grown up. At the age of sixteen, the little child was a lovely girl. The king and queen were very delighted. But the wicked fairy cast her spell. The girl, Sleeping Beauty, went to bed and fell fast asleep for a hundred years. One of the other fairies, a wise one, cast a spell to protect the castle, and all around there grew trees and bushes, making an impenetrable forest.

A hundred years passed, and a very nice prince went into the forest. The princess lived on, but the wicked fairy, the last one of the fairies, took a boat to all the lands far off. The prince hacked and hacked and hacked through the forest, and there was the castle. He broke in and went up to the bedroom.

There he found a girl and she was such a lovely girl that the prince kissed her. And at once the whole castle woke up again, the courtiers, the dancers and the princess. And she was very beautiful and she liked to dance, so the prince was delighted, and everyone was very happy.

\section{MC's reading of the text}

Once upon a time there was a prince and princess and they are going to a baby. The baby duly arrives. The gentry are present. In the gallery there are lots of fairies and... each one of them to baby and to a present. The wicked fairy ... erm... oh, I can't think of that word... cursed the spindle and said that would be baby should be touched to die. Well, sort of...oh dear.

A long time ago the princess has grown up. At sixteen the child was a lovely girl. The prince and princess were delighted. The wicked fairy cast the spell. The girl, the Sleeping Beauty, went to bed and fell fast asleep for a hundred years. One of the fairies, a wise one, put the spell to protect the castle, and all in all there are trees and bushes which, and, oh god, erm, terrible forest. A hundred years passed and the prince went into the forest. The prince hacked and hacked and hacked through the leaves and through the castle. The spell was broken and he went through the bedroom. There was a pretty girl and such a lovely girl that the prince kissed her. The whole castle awake, the courtiers, the guard, the dancers and the princess. And she is beautiful and danced. So the princess is delighted and everyone was happy. 